\title{
The experience of patients with $\mathrm{ABI}$ and their families during the hospital stay: A systematic review of qualitative literature
}

\author{
Tolu Oyesanya, MS, RN \\ Doctoral Candidate, University of Wisconsin-Madison, School of Nursing
}

\begin{abstract}
Background-Patients with acquired brain injury (ABI) and their families have unique experiences and needs during the hospital stay; yet, limited literature exists on this topic. The purpose of this systematic review was to compile and synthesize literature on the experience of patients with $\mathrm{ABI}$ and their families during the hospital stay.

Methods-A systematic review of qualitative studies was conducted by searching for studies from seven databases. Content analysis was used to analyze and synthesize studies' findings separately for the patient and family experience.
\end{abstract}

Results-The initial search provided 2,871 records. Ultimately, eleven studies relevant to the research question were included in this review. No studies were excluded based on critical quality appraisal. Findings on the patient experience showed patients had negative perceptions of the rehabilitation environment and a perceived need for information. Findings on the family experience included difficulty adjusting after the patient's injury, desire to be involved in the patient's care, mixed feelings about staff support, and high perceived need for information.

Conclusions-Findings provide awareness for healthcare providers on the multifaceted experiences of patients with $\mathrm{ABI}$ and their families during the hospital stay, strategies to make care more patient- and family-centered, and directions for future research.

\section{Keywords}

Brain Injuries; Hospitals; Patients; Caregivers

\section{Introduction}

\begin{abstract}
Acquired brain injury (ABI) may be defined as brain damage caused by events occurring after birth, as opposed to birth-related, genetic or congenital disorders [1]. Moderate-tosevere ABI encompasses brain damage with different etiologies, such as traumatic brain injuries (caused by a "bump, blow or jolt to the head or a penetrating head injury that disrupts the normal function of the brain" [2]) and stroke (caused by cerebral vascular accidents) [3]. High incidence rates of ABI occur in the United States, with over 2.5 million people sustaining traumatic brain injuries, and over 800,000 people experiencing a new or
\end{abstract}

Corresponding Author: Tolu Oyesanya, MS, RN, 5130 Signe Skott Cooper Hall, 701 Highland Avenue, Madison, WI 53705, toyesanya@wisc.edu, (414) 559-9923.

Conflicts of Interest: The author reports no declaration of interest. 
recurrent stroke event annually [4,5]. Moderate-to-severe ABI causes cognitive impairments such as problems with memory, attention, and executive function; difficulties with speech, communication; and decreased capacity for new learning [6,7]. Millions of people are currently living with the cognitive impairments and disabilities caused by ABI, with more than 6.4 million people living with the impairments caused by traumatic brain injury and stroke combined [3]. ABI is a chronic disease [8], and the outcomes have tremendous lifetime implications for patients and their families.

\section{Role and Needs of Family Members of Patients with ABI}

Family members play a large role in supporting their loved one through the difficult recovery and rehabilitation process that is necessary after a moderate-to-severe ABI [9]. This process causes a crisis for family members, as the sudden onset of their loved one's brain injury and critical and often changing status is overwhelming [10]. Throughout the hospital stay, family members support their loved ones with ABI by assisting with goal-planning and decisionmaking $[9,11]$ and providing physical, instrumental, and emotional support during the hospital stay and after discharge [12]. Also, family members often transition to the role of caregiver once patients are discharged from the hospital.

As family members often become caregivers of patients with moderate-to-severe ABI and continue supporting them after discharge, it is important to consider family needs [13]. Consideration of family caregivers' needs in the plan of care helps to ensure family caregivers are adequately prepared to care for their loved one after discharge. However, perhaps due to time constraints [14], the needs of family caregivers of patients with ABI are often not considered prior to the patient being discharged, as much of the focus is on the patient [15]. Consequently, some family caregivers perceive that they are not prepared to care for the patient with ABI when they are discharged home from the hospital [16]. The long-term care needs of both patients with $\mathrm{ABI}$ and their family caregivers suggest family caregivers' needs should be addressed as soon as possible, particularly during the hospital stay, as this will provide insight into how healthcare providers can meet their needs [17]. Thus, it is important to understand family caregivers' needs before they are discharged from the hospital to assist with adequate preparation for the caregiver role.

\section{Research on the Experience of Patients with $A B I$ and their Families}

While limited studies have examined the experience of patients with $\mathrm{ABI}$ and their family during the hospital stay, research exists that examines the patient and family experience after discharge. Research has shown that patients with ABI report unmet needs relating to support from healthcare providers after discharge [18,19], specific to the transition from hospital to home and help with emotional and behavioral problems. Other studies have shown that patients with $\mathrm{ABI}$ report needing more assistance from healthcare providers to address neuropsychological problems, such as emotional lability, memory, and problem solving [2022]. A systematic literature review focusing on needs of family caregivers of patients with ABI after discharge found families reported unmet needs, which were linked to a perceived need for more information [23]. Families also had unmet needs relating to emotional support and management of the patient's behavioral problems [23]. 
However, the majority of studies on the needs of patients with ABI and their families collected data on their experience long after the patient was discharged from the hospital (e.g., 3 months to several years) $[23,24]$. Collecting data long after the patient has been discharged from the hospital limits applicability to the patient's and family's experience and needs during the hospital stay for multiple reasons: 1) collecting data long after discharge may not accurately capture patient and family thoughts, feelings, and concerns as events occurred during the hospital stay [25];2) the needs of patients and families during the hospital stay are much different than their needs once discharged home, as research has shown their needs change over time [26]; 3) research has shown that when someone is asked to recall events that have long passed, bad memories are remembered more strongly than good memories, also known as negativity bias [27], so waiting until long after discharge to interview patients and families about their experience during the hospital stay may negatively influence their responses. Conversely, collected data on the experience of patients with $\mathrm{ABI}$ and their family members during the hospital stay can help healthcare providers understand their needs and adequately prepare them for discharge by making care more patient- and family-centered.

\section{Research on the Experience of Patients with Spinal Cord Injuries and their Families}

Spinal cord injury, defined as either "loss of voluntary movement (paralysis) [or] loss of sensation [28, p. 289], is a complex injury that, similar to ABI, causes physical, psychological, and social difficulties for both the patient and their family [29]. Spinal cord injuries commonly co-occur with traumatic brain injuries. Approximately $60 \%$ of people who sustain a spinal cord injury simultaneously sustain a brain injury, and up to $20 \%$ of those traumatic brain injuries are moderate-to-severe in nature [30].

Research on the experience of patients with spinal cord injuries and their families during the hospital suggests there may be more to learn about the experience of patients with $\mathrm{ABI}$ and their families during this time. Similar to patients with ABI, patients with spinal cord injuries report unmet needs during the hospital stay, including perceived the need for more information [31], desire to build stronger relationships with healthcare providers [31], desire to participate in rehabilitation planning [32], the need for more emotional support [32], and the need for family involvement in care [33,34]. After discharge, unmet needs for patients with spinal cord injury and their family members continue, including difficulty communication with healthcare providers [35], lack of post-discharge care [36], limited support from healthcare providers [36], and difficulty adjusting [37]. As there is limited research on the experience of the hospital stay for patients with $\mathrm{ABI}$ and their families, this body of research specific to spinal cord injury can be used to provide direction to researchers and healthcare providers on the patient and family experience after ABI.

\section{Research Recommendations from Prior Literature on ABI}

Although research, albeit limited, is available about the experience and needs of patients with moderate-to-severe ABI and their families both during and after the hospital stay, scholars have emphasized the need for more research. Even though the majority of research on this topic has been quantitative, findings of both quantitative and mixed-methods reviews emphasize the need for qualitative research to reinforce existing quantitative knowledge. For 
instance, a quantitative systematic review on the needs of patients with brain injury after discharge recommended that more research be done to help healthcare providers understand the needs of patients with ABI, specifying that "in-depth interviews could provide a clearer image of the actual needs and care required by patients" [24, p. 1204]. A systematic review that synthesized quantitative literature focusing on the needs of family caregivers of patients with $\mathrm{ABI}$ after the hospital stay emphasized that more research is needed "to determine whether current methods of analyses reveal an accurate representation of family needs" [23, p. 670]. Yet another systematic review, which was mixed-methods in nature, focused on the long-term care needs of patients with ABI and their families recommended more research be conducted to elucidate areas that patients and their families deem are important, which could be better understood through the voices of the patients and families [17]. These authors also noted that "more qualitative approaches to exploring TBI [traumatic brain injury] are an invaluable addition to the evidence base" [17, p. 606], and that this knowledge could help healthcare providers to learn about strategies to best support patients and families, which is vital to service planning and development [17]. These published recommendations for research emphasize the need for qualitative research methodologies to assist researchers and clinicians to better understand patient and family experiences and needs during the hospital stay.

Qualitative research methodologies are suitable to help researchers and clinicians to improve the accuracy and relevance of quantitative studies by helping to identify appropriate variables that are important to the population being studied and by providing explanations for findings that are unexpected or that were previously unexplainable [38]. As quantitative research alone may be unable to fully describe the experience of patients with ABI and their families during the hospital stay, qualitative research can be used to reinforce quantitative research and to provide directions to healthcare providers on how to make care more patientand family-centered. Therefore, there is a need to do a systematic literature review of qualitative research focusing on the experience of patients with moderate-to-severe $\mathrm{ABI}$ and their families during the hospital stay.

To address these gaps in knowledge and the above-listed research recommendations, it is important to capture and synthesize findings from qualitative research on the experiences of patients with $\mathrm{ABI}$ and their families during the hospital stay to build new knowledge and to provide directions for future research. As partnerships between patients, families, and healthcare providers "need to be forged as early as possible" [39, p. 23], this research can provide new knowledge in this area, which may assist healthcare providers to do the following: 1) understand the overall experience of the hospital stay for patients with ABI and their families; 2) improve how patients and families are prepared for discharge; 3) make care more patient- and family-centered; and, in turn, 4) improve self- and familymanagement of ABI after discharge. However, to do this, common themes among patients' and families' experiences are required and the needs of both should be identified [23]. To this end, a systematic literature review was conducted with the following aims:

1. To synthesize qualitative research on the experience of patients with moderateto-severe ABI during the hospital stay; 
2. To synthesize qualitative research on the experience of family members of patients with moderate-to-severe ABI during the hospital stay.

\section{Methods}

Study Design

This systematic literature review was conducted following guidelines put forth by the Centre for Review and Dissemination and by Butler (2016) [40,41]. The author used PRISMA (Preferred Reporting Items for Systematic Reviews and Meta-Analyses) guidelines to report findings [42]. The PRISMA flow diagram in Figure 1 describes the selection process.

\section{Eligibility Criteria}

General inclusion criteria were set for selecting studies from all databases. All literature searches were restricted by: period of publication (1990-2015), type of journal (academic peer-reviewed), language (English), research subject (human), and subject age (18 years or older). Specific inclusion and exclusion criteria governed the overall screening process, and were set for patients, family members, patients' diagnoses, study focus, type of studies, and setting. These criteria are listed in Table 1.

\section{Search Strategy}

The literature search was conducted between October 28 and November 11, 2015. The following electronic databases were searched: CINAHL, PsycInfo, PubMed, SocIndex, Academic Search Premier, Family Studies Abstracts, and Family and Society Studies Worldwide. An example of key words and phrases used in each database is listed in Table 2.

\section{Study Selection}

After obtaining all of the studies resulting from searching the seven electronic databases, the author saved all citations in a citation manager (Zotero). Prior to applying the inclusion/ exclusion criteria, duplicates were removed. The author and a research assistant independently screened the title and abstract of each study. Next, the author and research assistant discussed whether to include each study that met inclusion criteria by reading the full-text. Reference lists of each study that met inclusion criteria were hand-searched for additional studies on the topic.

\section{Data Extraction}

Data extraction were performed by the author and research assistant. All studies were coded deductively for the stated: a) author(s); b) year of publication; c) country; d) study purpose; e) study design; f) sample strategy; g) sample characteristics; h) data collection techniques; i) data analysis techniques; j) findings for patients' and families' experience relevant to the review.

\section{Critical Appraisal of the Quality of the Studies}

The author and research assistant used the QualSyst Tool for Qualitative Studies [43] to assess the quality of each study in this review. When discrepancies occurred, both discussed 
rationale for including or excluding studies until consensus was reached. The QualSyst Tool contains an individual checklist detailing criteria specific to qualitative studies [43]. Psychometric information for this tool has yet to be established.

\section{Analysis of Findings from Studies in this Review}

Findings across all studies were analyzed and synthesized using conventional content analysis, which was suitable to use as research on this experience is limited [44]. Following the steps outlined by Hsieh \& Shannon (2005), the author and research assistant first immersed themselves in the data by reading through each article to obtain a sense of the whole, writing notes while reading through to indicate first impressions. Next, codes were developed that were reflective of the data. Themes were developed by grouping codes based on similarities and differences and organizing codes into meaningful clusters [44]. Analysis for the patient and family experience occurred separately, resulting in two separate syntheses. Information on each study is presented in Table 4 to allow for comparison across articles.

\section{Results \\ Search Outcome}

The initial search identified 2,871 studies. A flow diagram describing the selection of studies is shown in Figure 1. After the initial search, all studies were imported into a citation manager, and 590 duplicates were removed. The first author and research assistant independently screened titles and abstracts for the remaining 2,286 studies. There were 76 studies that met inclusion criteria during this screening phase and were reviewed in full. Next, during the preliminary review of full-text of each study, 65 studies were excluded due to not meeting inclusion criteria for the following reasons: a) being a quantitative study $(n=5)$; b) conducting interviews greater than one month post-discharge $(n=28)$; c) lacking patient/family perspectives $(n=2)$; $)$ not separating patient/family perspectives $(n=1) ; e)$ lacking focus on brain injury (n=3); f) lacking focus on hospital experience ( $\mathrm{n}=9$ ); and $\mathrm{g}$ ) being grey literature $(n=17)$. Ultimately, 11 studies were included in this systematic literature review, including 5 studies identified through hand searching. The chosen studies varied based on design, population, aims, and findings.

\section{Quality of Study Methodology}

The QualSyst Tool was used to assess the quality of methodology in each study on 10 criteria items, which were scored as 0 (no), 1 (partial), and 2 (yes) [43]. Each study was given a total score and a summary score. A maximum total score of 20 and a maximum summary score of 1 is possible for each study (see Table 3). Instructions for scoring indicated by the QualSyst Tool were: 1) to obtain the total score, add all the criteria items together; and 2) to obtain the summary score, divide the total score by the total possible score. Studies that did not meet the minimum summary score of 0.55 defined by the QualSyst Tool's inclusion threshold were excluded [43]. Five studies received a summary score between 1.00 and 0.90 ; three studies ranged from 0.75 and 0.70 ; and three studies ranged from 0.65 to 0.55 . No studies were excluded based on critical quality appraisal. 


\section{Study Characteristics}

All studies were qualitative in nature, using the following study designs: unspecific qualitative approach $(n=4)$, phenomenology $(n=3)$, and grounded theory $(n=4)$. Data collection techniques included: semi-structured interviews $(n=10)$ and mixed-methods $(n=1$; i.e., interviews and surveys). All studies focused on at least some portion of the experience of the hospital stay for patients with brain injury $(n=4)$, their family members $(n=7)$, or both $(n=3)$. Each sample included at least one of the following: 1) patients that were hospitalized primarily for care relating to their ABI or had been discharged sone month post-discharge at the time of the study; and 2) family members of these patients. The sample sizes varied from one participant (a case study) to 38 participants.

Patient diagnoses included moderate-to-severe traumatic brain injury $(n=3)$, specified and unspecified acquired brain injury $(n=3)$, and stroke $(n=5)$. Samples included family members with the following relations to the patient: spouses/partners, parents, children, siblings, uncles, grandparents, or unspecified. When specified, ages of patients ranged from 18 to 64 years. Ages of family members were more commonly reported and ranged from 24 to 93 years. Although participants in each study were interviewed during the hospital stay or sone month post-discharge, there were large variations in data collection time points. Data collection time points included: pre-discharge, post-discharge, and over the course of the patient's recovery. Finally, studies were conducted in various countries or areas around the world, including: United States $(\mathrm{n}=6)$, Australia $(\mathrm{n}=2)$, United Kingdom $(\mathrm{n}=2)$, and Canada $(\mathrm{n}=1)$.

\section{Synthesis of Studies}

Patient Experience-Four studies [45-48] in this review had findings relevant to the experience of the hospital stay for patients with brain injury. There were two main themes synthesized from the literature, which included: 1) perceptions of rehabilitation and 2) perceived need for information. An overview of themes specific to the patient experience based on the synthesized literature is listed in Table 5.

Perceptions of Rehabilitation: Three studies [45,46,48] reported patients' experiences during inpatient rehabilitation, including their thoughts about the rehabilitation environment, relationships with healthcare providers, and excitement for discharge. This theme included sub-theme findings that focused on the patients' perceptions of: a) expectations for recovery; b) impact of the rehabilitation environment; c) perceptions of rehabilitation activities; d) perceived support; and e) perceptions about discharge.

Expectations for recovery: After being stabilized, patients with ABI began to look toward the future regarding their next step in the recovery process, including completing inpatient rehabilitation [46]. Some viewed inpatient rehabilitation as an extension of their hospital stay, while others assumed that engaging in inpatient rehabilitation would help them return to their pre-injury functioning prior to discharge [46]. As rehabilitation began, patients realized that their expectations for recovery were incongruent with the expectations staff held. Patients wanted to return to their pre-injury functioning, while staff wanted to see "small, but notable change in function" [46, p. 791]. 
Impact of the rehabilitation environment: Patients who were interviewed during inpatient rehabilitation reported negative perceptions of the rehabilitation environment, often referring to their stay in inpatient rehabilitation as "prison" [45]. Many of these negative connotations arose due to limited personal privacy, minimal privacy with visitors, and lack of outside space on the rehabilitation unit [45]. Noises and regulated mealtimes also felt unnatural to the patients. However, some patients regarded the rehabilitation environment as a place to build community and socialize. While positive comments were made about rehabilitation staff, patients that had negative comments perceived rehabilitation staff did not treat them with respect [45].

Perceptions of rehabilitation activities: Fleming [45] described how many patients undergoing rehabilitation felt that their time was not used meaningfully. While patients reported that engaging in therapy and rehabilitation activities was beneficial to their recovery, some patients reported feeling bored and stated rehabilitation activities did not have much meaning; many said much of the day was unstructured during rehabilitation. Patients reported being bored and frustrated as they spent time watching TV and socializing with other patients or visitors while waiting for their next therapy activity to begin. However, patients that were able to find other ways to occupy their time did not report these feelings [45].

Perceived support: During inpatient rehabilitation, patients with ABI reported that visits from family members and friends made their experiences positive [45]. Visitors often provided support in different ways, including "providing a connection to current events outside the rehabilitation unit, knowing and understanding the person, and providing emotional support" [45, p. 190]. In contrast, not having any visitors had a negative effect on patients.

Perceptions about discharge: Three studies [45,46,48] described patients' perceptions of discharge. Many patients reported perceiving discharge as an escape from inpatient rehabilitation [45]. Patients reported that preparing for discharge was a relief, with feelings of excitement and anticipation $[46,48]$. However, prior to discharge, patients had to determine their post-discharge destination, including returning home, going to live with someone, or going to a nursing home [46].

Perceived Need for Information—One study [47] detailed patients' need for information throughout their hospital stay, specifically indicating the types of information desired at specific times, including the following sub-theme time frames: a) immediately after injury; b) during acute care/rehabilitation; and c) before discharge.

Immediately after injury: Within two days of the ABI, patients who were cognizant wanted information that would help them to understand their diagnosis. Patients wanted to know the results of tests and "investigations" that were conducted, including seeing scans and x-rays. In particular, patients wanted to know about staff's recovery predictions. Patients with $\mathrm{ABI}$ reported that they wanted this information delivered by medical staff, both verbally and in writing to be able to reference later. Patients also reported that they wanted 
information about control of symptoms, such as pain, but requested that nurses, in no specific format, deliver this information [47].

During acute care/rehabilitation: Approximately 20 days post-injury, patients reported wanting much of the same information that they received immediately after injury. Patients recognized that they were likely "out of it" when staff initially provided them with information about test results and diagnosis. Patients also requested information detailing whether further tests were needed. Information about test results and the need for further testing was requested from anyone with sufficient knowledge, verbally and in writing. Patients also had concerns about long-term problems, wanted to speak with the nurse about pain control, and wanted advice on financial matters from social services staff [47].

Before discharge: Prior to discharge, at approximately 90 days post-injury, patients who were still undergoing inpatient rehabilitation wanted information about long-term recovery and recovery predictions from their general practitioner. Patients also wanted to know about caregiver support and benefits from social services staff, but did not have any preferences on the manner of delivery of this information. Finally, patients also wanted to hear first-hand from other people who had survived an ABI to learn about their experience [47].

\section{Family Experience}

Ten studies $[10,15,25,39,45-47,49-51]$ in this review had findings that were relevant to families' experiences of the hospital stay after their loved one had an ABI. Multiple themes for the family experience were synthesized from the literature, including: 1) adjustment after loved one's injury; 2) involvement in care; 3) dealing with the event; 4) perceptions of the patient's rehabilitation; 5) perceptions of relationships; 6) preparing for the upcoming caregiver role; and 7) perceived need for information. The majority of the themes have subthemes that provide a deeper description of the family experience. An overview of themes specific to the family experience based on the synthesized literature is listed in Table 5.

Adjustment after Loved One's Injury-Five studies [25,45,46,49,50] in this review discussed the theme "adjustment after loved one's injury," including descriptions of family members' negative emotions, and problems with decision-making. This theme had three sub-themes: a) emotional reactions; b) uncertainty; c) decision making; and d) difficulty with transitions.

Emotional reactions: Emotional reactions began for family members after the patient was admitted to the hospital for critical or acute care [46]. Many emotions surrounded the event of "getting the news," which left vivid memories for family members [50]. As the family members began to understand what happened, they experienced shock, disbelief, anxiety, stress, anger, confusion, loss of control, guilt, blame, and fear [25,46,49]. Many family members reported feeling relief that their family member survived and hoped that they would return to their pre-injury functioning [46]. Some family members reported blaming the patient, the patients' primary family caregiver (e.g., wife of patient) or medical personnel for lack of immediate recognition of the symptoms, especially when a stroke occurred [46]. Family members' emotions fluctuated over the course of the patient's hospital stay up until 
discharge from rehabilitation [49]. Emotions fluctuated depending on the time since injury and personality of the family member [25]. Many primary family caregivers had difficulty coming to terms with adjusting to life post-injury, with feelings of sadness and grief [45,49].

Uncertainty: After the patient was admitted to the hospital, family members felt uncertainty surrounding the patient's survival. Uncertainty was composed of: a) not knowing whether the patient would survive; b) waiting for information on the patient's injury and for the patient to wake up; c) uncertainty regarding the patient's prognosis and how much the patient's and family members' lives would change; and d) uncertainty about the patient's quality of life [50].

Decision-making: Decision making for these families was particularly difficult as families were uncertain about the prognosis of the patient's recovery. Many family caregivers reported having to make life-changing decisions in a short period of time with limited information [46]. Most families were concerned with the potential for cognitive deficits and changes in behavior. Given the difficulty predicting patient prognosis, many family members wanted to wait to make ethical decisions. If ethical decisions were made before it was clinically necessary, family members perceived this to mean they were "giving up hope and abandoning the injured family member" [25, p. 233].

Difficulty with transitions: According to Keenan and Joseph [50], transitioning to different levels of care was hard for families because they had to adjust to different staff, unit cultures, and a perceived delay in care as the patient was being assessed. Being on one unit for many weeks bred familiarity, and moving to a new unit with new staff was a big adjustment [50].

Involvement in Care-Three studies $[10,25,50]$ showed that many family members wanted to be directly involved in the patient's care in multiple ways such as physical presence and assisting staff with the patient. Involvement in care included the sub-themes: a) physical presence; b) hands-on actions; and c) other ways of involvement.

Physical presence: Because survival was questionable, the family members wanted to be physically present with their injured loved one [50]. Family members rushed to their loved one's bedside and had a difficult time leaving immediately after the injury. Many wanted to be present when their family member regained consciousness $[25,50]$. Family members reported wanting to be able to stay as long as possible, even though some hospital policies restricted amount of visitors and length of their stay, particularly in ICU [25]. This physical closeness made some families feel that they were involved in their loved one's care [50].

Hands-on actions: As the time progressed in the patient's ICU stay and as family members stayed long hours to support the patient, many family members expressed wanting to participate in the patient's care by doing hands-on actions. For instance, many wanted to assist with the patient's bath. However, some families reported never being given instructions on how they could help [10]. Family members that participated in "hands-on actions" for the patient reported that they felt involved in the patient's care [50]. 
Other ways of involvement: Families reported that being involved in the patient's care was meaningful to them. Family members were involved in multiple other ways, such as attempting to help staff understand the patient. Others attempted to be a patient advocate and to plan for the patient's future [50].

Dealing with the Event-Five studies [10,39,49-51] discussed the theme "dealing with the event." After making sense of the news, family members attempted to deal with the patient's brain injury in many different ways, such as receiving support, and using spirituality and acceptance, which was described in the following sub-themes: a) perceived support from the community; b) perceived support from staff; c) taking it one day at a time; d) spirituality; and e) accepting.

Perceived support from others in community: During ICU, other family members and friends gave emotional support to the patient's primary family caregiver and to the patient by visiting, calling, and sending cards with prayers and optimistic messages [39]. However, primary family caregivers reported phone calls from friends and family were overwhelming due to the volume. Having to spend time dealing with friends' and family members' questions left family caregivers fatigued as all of their energy was already going to the patient. Staff were able to assist with this issue by limiting the number of calls at the hospital and limiting visitation with extended family and friends [39].

As few primary family caregivers felt they obtained a full understanding of their family member's injury, many turned to their informal social network of healthcare providers composed of family and friends to seek advice, if available [39]. Primary family caregivers were also grateful when these family members and friends came to the hospital to visit and asked the "right" questions of staff [39].

During ICU, community members also provided instrumental support by delivering meals, providing transportation for primary family caregivers and other family members to and from hospital, transporting the patient's and/or primary family caregivers' children to activities, helping with home chores, and giving money [50]. During acute care, emotional support from friends and other family members ensured that the patient's primary family caregiver(s) did not feel alone. Instrumental support from insurance and work accommodations were also very helpful at this time [50].

Perceived support from staff: Primary family caregivers reported that support received from staff had a positive influence on their experience [50]. Some spoke positively about their interactions with staff, especially the nurses in the ICU. Family caregivers felt reassured when staff presented themselves as confident, knowledgeable, and honest. In contrast, family caregivers had concerns when they perceived staff to not know the patient, which made them feel "insecure about the care that was being given" [50, p. 29]. During acute care, support often came from the healthcare team as a whole. Some primary family caregivers reported nurses provided the most support, as nurses spent many intimate hours with the patient and family [50]. 
Taking it one day at a time: Throughout the recovery process, family members reported facing the unknown, as they did not know what was going to happen to the patient or themselves. Family members felt overwhelmed when they thought too far into the future, so they reported taking it one day at a time by focusing on the immediate and the known [49].

Spirituality: Primary family caregivers reported that their strong faith and spirituality helped to bring them through the ongoing crisis, maintain hope, and give them strength. They relied on their faith, even when they didn't have all the answers [10]. Camaraderie was also used to maintain hope, and primary family caregivers called on others with similar spiritual beliefs for help in maintaining hope [51].

Accepting: Families whose loved one's were severely injured began to accept that their lives would be forever changed by this injury. This was especially influenced by staffs' prognosis was that the patient would never be able to care for him/herself again and by the patient's marked cognitive changes, particularly because both would change roles and social interactions with family members [50].

Perceptions of the Patient's Rehabilitation-Eight studies [10,15,25,39,46,49-51] discussed the theme "perceptions of the patient's rehabilitation," which encompassed the family member's experience of the patient's stay in inpatient rehabilitation, particularly focusing on family members' involvement in the patient's care. This theme had multiple sub-themes, including: a) expectations for recovery; b) observing the patient's recovery; c) knowing the patient better; d) monitoring the patient's care; e) holding on to hope; and f) managing needs of the family.

Expectations for patient's recovery: After the patient was stabilized, family members began to look towards the future, particularly at the next step in the recovery process [46]. Both patients and their primary family caregivers were given the option of having the patient go to an inpatient rehabilitation unit, be placed in a nursing home, or go to sub-acute rehabilitation facility. Nursing home placement was not seen as a suitable option by most family caregivers [46]. Many families perceived that if the patient went to inpatient rehabilitation, they would not be discharged until they returned to their pre-injury abilities. Unfortunately, many family members "did not understand the scope of the decision to which they were committing" [46, p. 790].

Observing the patient's recovery: Family caregivers described a perceived association between involvement of family and the patient's recovery. For instance, family members noted that the perception that if family was present and involved, the patient seemed to recover faster [51]. Many families wanted to be present to monitor the patient closely for indicators of progress, which was sometimes inhibited by restrictions on the length of time they could spend visiting their loved one [10]. The patient's daily behaviors also influenced the family's feeling about the patient's recovery, with families reporting feeling positive when the patient progressed and disheartened when the patient regressed [50].

Knowing the patient better: Many family caregivers reported observation of daily improvements to use in determining the patient's progress. Family caregivers often reported 
that they believed that they knew the patient better than staff; some stated that they had the ability to identify behaviors that were present pre-injury as they emerged during the patient's recovery, such as mannerisms, subtle movement, and comments. This helped to reaffirm that progress was being made. Family caregivers felt that this "inside" knowledge helped them to see improvements that the nurses and other staff could not see, as staff did not know the patient pre-injury [51]. Other family members felt the information they provided to staff about the patient's pre-injury abilities and problems with their ongoing care were not actively used [39]. Some caregivers with active healthcare experience took a more active approach to try to convince staff to use the information they provided, while those without experience often did not know what to do and became concerned about the quality of care their family member was receiving [39].

Monitoring the patient's care: Some family members reported being very vigilant with the patient's care and progress [50]. Many relied on staff to provide the best care for their loved one but often found the patient was frequently waiting for care because staff were busy. This led to family caregivers monitoring how staff provided care to the patient, causing family caregivers to spend long hours at the hospital [39].

Holding on to hope: Family members attempted to maintain hope throughout the patient's hospital stay and recovery process, particularly during inpatient rehabilitation. Various levels of hope were held: where some families had a positive outlook, others lost hope and felt that things would not improve [50]. For many family members, specific events or interactions influenced their levels of hope. Family caregivers reported observation of the patient daily and recognition of the patient's improvements reinforced the caregiver's hope [51]. By focusing on the known rather than the unknown, hope was also fostered [49]. Families often relied on staff to maintain hope and were very cognizant of staff's words of encouragement [50].

All family members expressed hope for their loved one's future, including completing school or being able to regain employment. However, no caregivers expressed hope for the patient to resume activities of daily living, implying that activities of daily living were an automatic expectation [51]. As time went on, thoughts changed from hope for specific things to a general hopefulness that the patient would continue to get better [49].

Managing needs of the family: Immediately after the patient's injury and the first weeks following, family members reported focusing solely on the patient and postponing or delaying other responsibilities [50]. When it was clear the patient would survive, often when the patient began inpatient rehabilitation, the families adjusted and realized "other family obligations, work, and community life must take precedence" [50, p. 29], including sleeping and eating [25]. Many families reported role reversals, where primary family caregivers took on the pre-injury roles of the patient in addition to assuming their own prior roles [15]. Some also took on additional responsibilities, such as caring for the patient's children. As family functioning was disrupted [39], new routines needed to be developed for caring for other children at home [15]. 
Many family members gave up activities and commitments that were scheduled pre-injury, such as going on vacations and trips, volunteering, attending church activities, and socializing with friends [15]. Financial decisions changed, particularly if the injured person was the primary wage earner prior to injury. Many family members worried about what their life would be like after discharge, especially as it related to money [25].

Perceptions of Relationships-Four studies [10,25,50,51] discussed the theme "perceptions of relationships," including multiple types of relationships with family, staff, and friends, with the following sub-themes: a) family-family; b) family-friend; and c) family-staff.

Family-family relationships: Family-family relationships played a significant role in this experience. The stressful events, including the uncertainty of the patient's recovery, created interpersonal conflict in the family. For families that already had interpersonal conflicts prior to injury, this situation intensified their conflicts. Presence of interpersonal conflicts made it even more difficult to deal with the patient's injury [50]. Strong marital relationships with clear communication were present, but the stress of the patient's injury created tension $[25,51]$.

Family-friend relationships: Relationships with friends and other acquaintances were important, particularly in the first few days after injury. However, some family members reported wanting to be alone at this time. As the patient's recovery progressed, the continuing presence of friends became tiring to family members [25].

During critical care, relationships with other families began to form. Many of these relationships were built as families sat in the waiting room patiently awaiting the next time they could go into their family member's hospital room for a short visit [25].

Family-staff relationships: Many family members reported disappointment if they did not have the opportunity to talk with their loved one's physician each day [25], and some even reported not being able to speak with the patient's physician for a few days after the hospital stay began [10]. Many wanted regular updates on the patient's condition, even if there were no changes [25]. However, some families reported that the less they saw the patient's physician, the less discouraging news they would have to hear [25]. Regarding family-nurse relationships, many families reported positive relationships with nursing staff [25]. Nurses were often helpful in filling in missing information after discussions with physicians [25]. However, visiting restrictions in the ICU created conflicted between families and nurses [25]. Family-staff trust was established when information was delivered in a consistent, caring, and understandable manner. Positive interactions reinforced trust, while negative interactions diminished it [50].

Preparing for Upcoming Caregiver Role-Three studies [39,46,49] discussed the theme "preparing for the upcoming caregiver role." While discharge was highly anticipated by both the patient and family caregiver, much work was required of family caregivers before the patient was discharged, including gaining knowledge and skills and preparing to 
accommodate the patient post-discharge. Sub-themes included: a) attempting to gain knowledge and skills; b) gaining confidence; and c) crisis of discharge.

Attempting to gain knowledge and skills: Primary family caregivers were motivated to seek the best care for their loved one, leading to a desire to be competent as a family caregiver. After realizing they would need to care for the patient post-discharge, family caregivers wanted to become actively involved in the patient's care but often felt that doing so was infringing on staff's territory. Family caregivers felt that their attempts to gain knowledge and skills necessary to care for their loved one were unheeded. However, some family caregivers reported they were able to overcome resistance from the staff [39].

Gaining confidence: Primary family caregivers' gained confidence to care for their injured loved one when staff whom caregivers perceived to be confident taught them skills. However, most family caregivers reported limited time to prepare them for their loved one's discharge, which led to additional stress and lack of confidence [39].

Crisis of discharge: The patient's impending discharge caused a crisis for family members, particularly primary family caregivers [49]. It was often not until one or two days prior to discharge that caregivers began to realize that the patient was going to be discharged even if they had not met the family caregiver's initial recovery expectations. Family caregivers had to quickly determine what was needed to accommodate the patient after discharge and who would be able to do help. An endless list of tasks and responsibilities was determined, including physical, emotional, and instrumental support. Family caregivers were also expected to attend the patient's therapy and rehabilitation sessions before discharge to receive training on how to care for the patient. The sheer amount of preparation and training made most family caregivers exhausted [46].

Perceived Need for Information-Six studies [10,25,39,45,47,50] discussed the theme "perceived need for information." Throughout the patient's hospital stay, families reported an intense need for information, wanting to know about their loved one's injury and their prognosis $[10,25,39,45,47,50]$. Families reported wanting information that was consistent, easy to understand, specific to their relative (not probabilities or statistics), with frequent updates [50]. Many family members reported the following sub-themes: a) lack of understanding of information; b) wanting certain types of information; c) problems accessing staff and information; and d) wanting no assumptions.

Lack of understanding of information: Information in many forms (given, received, perceived, interpreted) played a large role in the decisions made by family members [25]. Although family members could repeat information on the patient's status, some reported that that they "had not grasped the meaning of the information" [25, p. 233].

Wanting certain types of information: Many family caregivers were uncertain about the injury and what it meant for the patient and themselves. Family members sought knowledge and understanding relating to the injury [39,50], including verbal and written information about diagnosis, prognosis, results of tests, prescribed medications, and possible interventions $[10,47]$. Others wanted knowledge about expectations of the rehabilitation 
process, treatment goals and outcomes, available resources [45], information about longterm consequences (e.g., recovery of speech, sexual needs) and the impact these consequences would have on the patient's discharge [47]. Some families reported wanting this information from a single doctor, especially early in the patient's care [10]. Regardless, family caregivers wanted this information to be truthful and consistent and having to ask for this above-listed information led to more stress [10]. Family members wanted this information communicated freely, without having to ask for it, as asking felt intrusive [10]. Often times, when this information was not given, family members became concerned that they lacked knowledge and would be unable to fulfill the role of caregiver [45].

Problems accessing staff and information: In regards to attempts to receive information, some families felt that staff were easily accessible, while other family members who were unavailable during business hours reported difficulty gaining access to information they desired from staff due to communication barriers. Those who had difficulty communicating with staff had doubts about their own abilities to provide effective care to the patient after discharge [45]. Sometimes, when it was not easy to access desired information, family members used both subtle and explicit techniques to obtain information, such as asking direct questions, observing, or even eavesdropping on patient-staff interactions. Having to seek information in this manner made family members feel as if they were going it alone [39]. Finally, family members reported that family meetings with staff were very helpful in receiving information. However, families stated more family meetings were necessary to make sure there was clear and consistent information being communicated [45].

Wanting no assumptions: Many family members reported being overwhelmed, even if they had prior experience visiting other sick family members in the hospital, or even if they had healthcare experience (e.g., practicing nurse). Family caregivers with healthcare experience reported that their healthcare experience was a barrier, as staff made assumptions about their levels of knowledge about ABI, thus limiting information provided to them [39]. Family caregivers reported that, regardless of healthcare experience, they wanted as much information as possible to help them become knowledgeable about the patient's status and necessary future care [39].

\section{Discussion}

The purpose of this systematic literature review was two-fold: 1) to compile and synthesize the research on the experience of patients with moderate-to-severe ABI during the hospital stay; and 2) to compile and synthesize the research on the experience of family members of the same patients during the hospital stay. Across qualitative methodologies, very similar themes were present when patients and families were allowed to speak for themselves. Although the experience for patients with ABI compared to family caregivers varied, common themes were present among each group. Findings specific to the patient experience showed that patients with ABI had negative perceptions of the rehabilitation environment and had a perceived need for information. Findings specific to the family experience were multifaceted, characterized by family members reporting difficulty adjusting after the injury, a desire to be involved in the patient's care, mixed feelings about support from and 
relationships with staff, attempts to become prepared for the caregiver role, and a high perceived need for information.

The two main themes that characterized the literature on the patient experience were perceptions of rehabilitation and perceived need for information. While these findings are similar to the experience of the hospital stay for patients with spinal cord injury [31-33], these findings differ from literature on the experience of patients with ABI post-discharge. A systematic review on the care needs of patients with $\mathrm{ABI}$ after discharge showed patients reported different types of needs, including cognitive, emotional, and behavioral needs [24]. Cognitive needs included assistance with memory problems. Emotional needs were reported as wanting help with controlling one's moods, while behavioral needs focused on controlling one's temperament [24]. Taken together, this study's findings of the need for information during the hospital stay and findings from prior research on patients' long-term care needs are likely indicative of the patients' desire for self-management of injury after discharge. These findings emphasize the need for patient-centered care to increase patient's preparation for discharge, which aims to develop a partnership between patients and healthcare providers, increasing patient participation and patient-provider collaboration [52].

Only four studies on patients' experience were included in this study. Although patients with $\mathrm{ABI}$ are the ones spending all of their time at the hospital when receiving care immediately after a brain injury, few studies exist detailing their experience. Patients with ABI may have been systematically excluded from research on about their experience during the hospital stay due to the perception that the cognitive impairments caused by the injury inhibit them from providing meaningful information [53]. However, depending on the severity of patient's injury, patients may still be able to share their experience. Researchers' and healthcare providers' negative perceptions about the abilities of people with cognitive impairments to meaningfully participating in research have been documented in the literature, such as with people with intellectual disabilities or dementia [53,54]. Yet, research has shown that strategies can be used to facilitate effective interviewing with people with cognitive impairments, such as using shorter questions with active verbs and avoiding abstract concepts [54]. Question development should also take into account the patient's level of communicative competence, based on first- and second-order theory of mind (firstorder: ability to understand another person's thoughts; second-order: ability to conclude what one person is thinking about another person's thoughts) [55]. The findings from this study provide evidence that researchers were able to successfully interview patients with ABI during the hospital stay, as patients provided meaningful information on their experience. These patients' perspectives can be used to improve the rehabilitation environment to make care more patient-centered.

In contrast to themes about patients' experience, this study's findings on the family experience during the hospital stay were characterized by multiple themes, including: 1) adjustment after loved one's injury; 2) involvement in care; 3) dealing with the event; 4) perceptions of the patient's rehabilitation; 5) perceptions of relationships; 6) preparing for the upcoming caregiver role; and 7) perceived need for information. However, two themes from the family member's experience were also present in the patient's experience: perceptions of rehabilitation and perceived need for information. Many of these themes 
detail families' experience of fluctuating emotions, heightened uncertainty regarding decision-making, positive support from family and friends, and mixed feelings on support from healthcare professionals. These findings also emphasize families' use of multiple strategies to cope with their loved one's injury and apprehension about and difficulty with preparing for their upcoming caregiver role. These findings are similar to results from other studies, which focused on the needs of family members of patients with ABI after the hospital stay, as well as studies detailing the experience of family members of patients with spinal cord injuries [34-37]. For instance, a mixed-methods systematic literature review on support needs of family members of patients with ABI showed that families reported multiple support needs, including informational, emotional, and practical support [56]. Examples of their needs included wanting: 1) quality information about the patient's symptoms [12,57]; brain injury care [58,59] and prognosis [60]; 2) their emotions to be taken into account by healthcare providers [61]; and 3) to participate in the patient's care [62] and decision making [63].

Findings on the family experience from this systematic review can also be used to reinforce results from other studies, particularly studies using quantitative methodologies. The themes relating to the family experience in this review, such as "preparing for the upcoming caregiver role" and "perceived need for information," truly emphasize that family members have a desire to be adequately prepared to care for the patient after discharge. These findings provide depth to quantitative research on this topic. More specifically, research has found after a patient with ABI leaves the hospital, family members report that $30-60 \%$ of their needs go unmet relating to care and support of the patient $[21,22,64]$. After discharge from inpatient rehabilitation, other studies show family members stated they felt that their needs were unmet because the service system was unorganized, uncaring, and unresponsive [62], limiting the family's ability to support the patient. Taken together, our findings and those from prior research emphasize family members' desire to be adequately prepared to support and care for their loved one after the hospital stay, suggesting a need for care to be more family-centered during the hospital stay to assist with meeting family members' needs. In addition, these findings shed light on areas that need further research and provide direction for researchers on new variables to test.

Perhaps our most interesting finding was that family members' reported a desire to be more prepared to care for their loved ones after discharge, which emphasizes the need for familycentered care. A family-centered care model can help to meet families' needs through family-provider partnerships focusing on emotional, social, and developmental support and promoting the well-being of the patient and the family [52]. As families play a significant role in supporting the patient during the hospital stay $[9,11]$, a family-centered model of care can begin to address both patient and family needs before the patient is discharged [52].

\section{Practice Implications}

Taken together, findings from this study and prior research provide awareness for healthcare providers on the multifaceted experiences of patients' with ABI and their families during the hospital stay, providing direction on how to make care more patient- and family-centered. Patient- and family-centered care emphasizes the importance of having a partnership 
between patients, their families, and healthcare providers in goal setting and decisionmaking [52], throughout the hospital stay and especially during rehabilitation. As patients and families move through their experience of the hospital stay, it is clear that they have expectations of healthcare providers, including being listened to, receiving support, receiving information, and being prepared for self- and family-management of injury. Healthcare providers' awareness of these expectations can be used as a first step in making care more patient- and family-centered for patients with ABI and their families.

More specifically, knowledge that patients perceive the rehabilitation environment lacks privacy and that unstructured activities cause boredom and frustration may provide direction on how to improve inpatient rehabilitation for patients with ABI. Discrepancies in expectations in recovery for patients' and their families compared to healthcare providers may suggest a need for more inclusion of patients and families in goal setting and interdisciplinary team meetings, particularly during inpatient rehabilitation. Understanding of how family members attempt to deal with their loved one's injury may give healthcare providers insight into strategies some families use to cope, which providers may be able to directly apply to their own practice. Cognizance of family caregivers' attempts to become adequately prepared for the caregiver role may suggest a need for more focused family caregiver training throughout the hospital stay, in conjunction with typically scheduled family caregiver training during the patient's rehabilitation therapy sessions. Awareness of patients' and families' perceived need for information throughout the hospital stay may provide guidance on exactly what information to provide to patients and families and the appropriate timing to do so.

\section{Limitations}

This systematic literature review only included studies published in English in peer-reviewed journals, which may have excluded relevant studies published in other languages. However, the findings of this study provide direction for future research on this topic. This review focused on studies that collected data on the patient and family experience during the hospital stay or less than one month post-discharge. While this may have excluded other studies on this topic that collected data more that one month post-discharge, the author chose this data collection time frame as it captured an accurate portrayal of the literature on this topic by collecting data from participants while they were actively engaged in the events. This study also combined literature on moderate-to-severe ABI, including specified and unspecified ABI, traumatic brain injury, and stroke and also did not include other causes of brain injury in the search strategy. Although these injuries have different etiologies, much of the care provided to patients with $\mathrm{ABI}$ and their families after injury and over the recovery trajectory is similar.

\section{Future Research}

Future research is needed to provide more depth to current literature on the experience of the hospital stay for patients with ABI and their families. First, more studies are needed to better understand patients' and families' experiences of the hospital stay, including studies focusing on differences based on age of the patient and cause of injury (e.g., TBI vs. stroke). The results of this review provide evidence that patients with $\mathrm{ABI}$ are able to provide 
meaningful information about their experience during the hospital stay. Instead of minimizing patient's abilities after ABI, researchers should determine questions patients are able to answer and work to capture their experience. While studies about patients with ABI and their families can be applied to the experience of patients with TBI and their families, more research is needed to elucidate the experience of patients with TBI and their families during the hospital as only three studies in this review focused specifically on TBI.

Additional research on this topic will help to increase both healthcare providers' and researchers' knowledge of specific their needs during this time. Second, more rigorously conducted research is needed as many studies had flaws in study aims and objectives, data collection techniques and time frames, and data analysis. Some studies' findings in this review did not specify timeframes for the participant experiences, including not specifying the hospital units participants were on or were referring to during interviews and not specifying the patient's time since injury.

Similarly, few studies in this review detailed the actual questions asked of participants during interviews; some provided examples of a few interview questions, others provided information on topics discussed during interviews, and others provided no information. To improve existing and forthcoming knowledge on the patient and family experience, researchers need to detail the interview questions asked of participants so researchers and clinicians can understand what was specifically asked about their experience, how this relates to patient and family needs, and what questions are left to be asked. Third, while it is beneficial to ask patients and families about their experience, it is essential to determine exactly what patients and families want or what would have been helpful to them, which could be asked as a direct question. For instance, towards the beginning of inpatient rehabilitation, a clinician could ask the family caregiver, "What are your concerns for when your family member returns home from the hospital?" In addition, three to five days before discharge, a researcher or healthcare provider could ask the family caregiver, "What hasn't been done so far that would be helpful to you before your family member is discharged?" Finally, as family members report spending long hours at the hospital to support their loved one physically and emotionally [25,50], more research is needed to determine the work that the family perceives they are doing during the hospital stay.

\section{Conclusions}

Patients with moderate-to-severe ABI and their families spend a significant amount of time at the hospital immediately after the patient's injury and throughout recovery and rehabilitation. Both patients and family members have perceptions about the events they face, as well as expectations of healthcare providers, including receiving support from professionals, providing information, and being prepared for discharge. Understanding more about patients' and families' experiences can assist healthcare providers in meeting the needs of patients with $\mathrm{ABI}$ and their families during the hospital stay.

\section{Acknowledgments}

Special thanks to dissertation committee members: Barbara Bowers, PhD, RN, FAAN (Chair); Lyn Turkstra, PhD, CCC-SLP; Barbara King, PhD, NP; Molly Carnes, MD, MS; Audrey Tluczek, PhD, RN; and David Maiers, PT. Thank you to research assistant, Mitchell Thomas, for assistance with literature search and review, quality assessment, and data extraction. Thank you the UW Institute for Clinical \& Translational Research (ICTR). 
This research was funded by the National Institute of Nursing Research (NINR) and the Eunice Kennedy Shriver National Institute of Child Health \& Human Development (NICHD) (PI, T. Oyesanya), Grant \#F31NR015398; by the University of Wisconsin-Madison, School of Nursing; and by the NIH/NIGMS Initiative for Maximizing Student Development (PI, M. Carnes) Grant\# R25GM083252. This project was partially supported by the Clinical and Translational Science Award (CTSA) program, through the NIH National Center for Advancing Translational Sciences (NCATS), grant UL1TR000427. The content is solely the responsibility of the authors and does not necessarily represent the official views of the NIH.

\section{References}

1. Ciuffreda KJ, Kapoor N, Taub M, Bartuccio M, Maino D. Acquired brain injury. Visual diagnosis and care of the patient with special needs Philadelphia: Wolters Kluwer Health/Lippincott Williams \& Wilkins. 2012:95-100.

2. Centers for Disease Control and Prevention. Traumatic brain injury. 2013. http://www.cdc.gov/ traumaticbraininjury/

3. Brain Injury Association of America. What is the difference between an acquired brain injury and a traumatic brain injury?. http://www.biausa.org/FAQRetrieve.aspx?ID=43913. Published 2015

4. Centers for Disease Control and Prevention. Report to Congress on Traumatic Brain Injury in the United States: Epidemiology and Rehabilitation. Atlanta, GA: National Center for Injury Prevention and Control; Divison of Unintentional Injury Prevention; 2014.

5. Lloyd-Jones D, Adams RJ, Brown TM, Carnethon M, Dai S, De Simone G, Ferguson TB, Ford E, Furie K, Gillespie C, et al. Heart disease and stroke statistics-2010 update A report from the American Heart Association. Circulation. 2010; 121(7):e46-e215. [PubMed: 20019324]

6. Dikmen SS, Machamer JE, Winn HR, Temkin NR. Neuropsychological outcome at 1-year post head injury. Neuropsychology. 1995; 9(1):80.

7. Lyon BL. Psychological stress and coping: framework for poststroke psychosocial care. Topics in stroke rehabilitation. 2002; 9(1):1-15.

8. Corrigan JD, Hammond FM. Traumatic brain injury as a chronic health condition. Archives of physical medicine and rehabilitation. 2013; 94(6):1199-1201. [PubMed: 23402722]

9. Lefebvre H, Pelchat D, Swaine B, Gélinas I, Levert MJ. The experiences of individuals with a traumatic brain injury, families, physicians and health professionals regarding care provided throughout the continuum. Brain Injury. 2005; 19(8):585-597. [PubMed: 16175812]

10. Bond AE, Draeger CRL, Mandleco B, Donnelly M. Needs of Family Members of Patients With Severe Traumatic Brain Injury. Critical Care Nurse. 2003; 23(4):63. [PubMed: 12961784]

11. Pegg PO Jr, Auerbach SM, Seel RT, Buenaver LF, Kiesler DJ, Plybon LE. The impact of patientcentered information on patients' treatment satisfaction and outcomes in traumatic brain injury rehabilitation. Rehabilitation Psychology. 2005; 50(4):366.

12. Rotondi AJ, Sinkule J, Balzer K, Harris J, Moldovan R. A qualitative needs assessment of persons who have experienced traumatic brain injury and their primary family caregivers. The Journal of Head Trauma Rehabilitation. 2007; 22(1):14-25. [PubMed: 17235227]

13. Levack WM, Siegert RJ, Dean SG, McPherson KM. Goal planning for adults with acquired brain injury: How clinicians talk about involving family. Brain Injury. 2009; 23(3):192-202. [PubMed: 19205955]

14. Bull MJ, Kane RL. Gaps in discharge planning. Journal of Applied Gerontology. 1996; 15(4):486500.

15. Silva-Smith AL. Restructuring life preparing for and beginning a new caregiving role. Journal of Family Nursing. 2007; 13(1):99-116. [PubMed: 17220384]

16. Weiss ME, Piacentine LB. Psychometric properties of the readiness for hospital discharge scale. Journal of Nursing Measurement. 2006; 14(3):163-180. [PubMed: 17278337]

17. Kneafsey R, Gawthorpe D. Head injury: Long-term consequences for patients and families and implications for nurses. Journal of Clinical Nursing. 2004; 13(5):601-608. [PubMed: 15189413]

18. Turner BJ, Fleming J, Ownsworth T, Cornwell P. Perceived service and support needs during transition from hospital to home following acquired brain injury. Disability \& Rehabilitation. 2011; 33(10):818-829. [PubMed: 20812814] 
19. Cain CH, Neuwirth E, Bellows J, Zuber C, Green J. Patient experiences of transitioning from hospital to home: an ethnographic quality improvement project. Journal of Hospital Medicine. 2012; 7(5):382-387. [PubMed: 22378714]

20. Corrigan JD, Whiteneck G, Mellick D. Perceived needs following traumatic brain injury. The Journal of Head Trauma Rehabilitation. 2004; 19(3):205-216. [PubMed: 15247843]

21. Heinemann AW, Sokol K, Garvin L, Bode RK. Measuring unmet needs and services among persons with traumatic brain injury. Archives of Physical Medicine and Rehabilitation. 2002; 83(8):1052-1059. [PubMed: 12161825]

22. Pickelsimer EE, Selassie AW, Sample PL, Heinemann AW, Gu JK, Veldheer LC. Unmet service needs of persons with traumatic brain injury. The Journal of Head Trauma Rehabilitation. 2007; 22(1):1-13. [PubMed: 17235226]

23. Sinnakaruppan I, Williams DM. Family carers and the adult head-injured: A critical review of carers' needs. Brain Injury. 2001; 15(8):653-672. [PubMed: 11485607]

24. Jennekens N, Casterlé D, Dierckx B, Dobbels F. A systematic review of care needs of people with traumatic brain injury (TBI) on a cognitive, emotional and behavioural level. Journal of Clinical Nursing. 2010; 19(9-10):1198-1206. [PubMed: 20500336]

25. Mirr M. Factors affecting decisions made by family members of patients with severe head injury. Heart \& Lung. 1991; 20(3):228-235. [PubMed: 2032859]

26. Kolakowsky-Hayner SA, Miner KD, Kreutzer JS. Long-term life quality and family needs after traumatic brain injury. The Journal of Head Trauma Rehabilitation. 2001; 16(4):374-384. DOI: 10.1097/00001199-200108000-00007 [PubMed: 11461659]

27. Baumeister RF, Bratslavsky E, Finkenauer C, Vohs KD. Bad is stronger than good. Review of General Psychology. 2001; 5(4):323.

28. Crewe NM, Krause JS. Spinal cord injury. Medical, psychosocial and vocational aspects of disability Athens: Elliott and Fitzpatrick. 2009:289-304.

29. Singh A, Tetreault L, Kalsi-Ryan S, Nouri A, Fehlings MG. Global prevalence and incidence of traumatic spinal cord injury. Clin Epidemiol. 2014; 6:309-331. DOI: 10.2147/CLEP.S68889 [PubMed: 25278785]

30. Macciocchi S, Seel RT, Thompson N, Byams R, Bowman B. Spinal cord injury and co-occurring traumatic brain injury: assessment and incidence. Archives of Physical Medicine and Rehabilitation. 2008; 89(7):1350-1357. DOI: 10.1016/j.apmr.2007.11.055 [PubMed: 18586138]

31. Garrino L, Curto N, Decorte R, Felisi N, Matta E, Gregorino S, Actis MV, Marchisio C, Carone R. Towards personalized care for persons with spinal cord injury: a study on patients' perceptions. The Journal of Spinal Cord Medicine. 2011; 34(1):67-75. [PubMed: 21528629]

32. Sand A, Karlberg I, Kreuter M. Spinal cord injured persons' conceptions of hospital care, rehabilitation, and a new life situation. Scandinavian Journal of Occupational Therapy. 2006; 13(3):183-192. [PubMed: 17042466]

33. Lindberg J, Kreuter M, Taft C, Person L-O. Patient participation in care and rehabilitation from the perspective of patients with spinal cord injury. Spinal Cord. 2013; 51(11):834-837. DOI: 10.1038/sc.2013.97 [PubMed: 23999110]

34. Lindberg J. Family members' perspectives on patient participation in spinal cord injury rehabilitation. International Journal of Physical Medicine \& Rehabilitation. 2014; 02(05)doi: 10.4172/2329-9096.1000223

35. Conti A, Garrino L, Montanari P, Dimonte V. Informal caregivers' needs on discharge from the spinal cord unit: analysis of perceptions and lived experiences. Disability and Rehabilitation. 2016; 38(2):159-167. [PubMed: 25858628]

36. Dickson A, Ward R, O'Brien G, Allan D, O'Carroll R. Difficulties adjusting to post-discharge life following a spinal cord injury: An interpretative phenomenological analysis. Psychology, Health \& Medicine. 2011; 16(4):463-474.

37. Dickson A, O'Brien G, Ward R, Allan D, O'Carroll R. The impact of assuming the primary caregiver role following traumatic spinal cord injury: an interpretative phenomenological analysis of the spouse's experience. Psychology and Health. 2010; 25(9):1101-1120. [PubMed: 20204960]

38. Black N. Why we need qualitative research. Journal of Epidemiology and Community Health. 1994; 48(5):425. [PubMed: 7964349] 
39. Brereton L, Nolan M. 'Seeking': A key activity for new family carers of stroke survivors. Journal of Clinical Nursing. 2002; 11(1):22-31. [PubMed: 11845752]

40. Butler A, Hall H, Copnell B. A guide to writing a qualitative systematic review protocol to enhance evidence-based practice in nursing and health care. Worldviews Evidence Based Nursing. Jan.2016 doi: 10.1111/wvn.12134

41. Centre for Review and Dissemination. Systematic Reviews: CRD's Guidance for Undertaking Reviews in Health Care. York: University of York; 2009. http://www.thelancet.com/pdfs/journals/ laninf/PIIS1473309910700657.pdf

42. Moher D, Liberati A, Tetzlaff J, Altman DG. Preferred reporting items for systematic reviews and meta-analyses: the PRISMA statement. Annals of Internal Medicine. 2009; 151(4):264-269. [PubMed: 19622511]

43. Kmet, LM., Lee, RC., Cook, LS. Standard Quality Assessment Criteria for Evaluating Primary Research Papers from a Variety of Fields. Alberta Heritage Foundation for Medical Research; 2004.

44. Hsieh H-F, Shannon SE. Three approaches to qualitative content analysis. Qualitative health research. 2005; 15(9):1277-1288. [PubMed: 16204405]

45. Fleming J, Sampson J, Cornwell P, Turner B, Griffin J. Brain injury rehabilitation: The lived experience of inpatients and their family caregivers. Scandinavian Journal of Occupational Therapy. 2012; 19(2):184-193. [PubMed: 21936734]

46. Lutz BJ, Ellen Young M, Cox KJ, Martz C, Rae Creasy K. The crisis of stroke: Experiences of patients and their family caregivers. Topics in Stroke Rehabilitation. 2011; 18(6):786-797. [PubMed: 22436315]

47. Garrett D, Cowdell F. Information needs of patients and carers following stroke. Nursing Older People. 2005; 17(6):14-16.

48. Turner B, Fleming J, Ownsworth T, Cornwell P. Perceptions of recovery during the early transition phase from hospital to home following acquired brain injury: A journey of discovery. Neuropsychological Rehabilitation. 2011; 21(1):64-91. DOI: 10.1080/09602011.2010.527747 [PubMed: 21132603]

49. Fraser C. The experience of transition for a daughter caregiver of a stroke survivor. The Journal of Neuroscience Nursing. 1999; 31(1):9-16. [PubMed: 10207828]

50. Keenan A, Joseph L. The needs of family members of severe traumatic brain injured patients during critical and acute care: A qualitative study. Canadian Journal of Neuroscience Nursing. 2010; 32(3):25-35. [PubMed: 20865832]

51. Gebhardt MC, McGehee LA, Grindel CG, Testani-Dufour L. Caregiver and nurse hopes for recovery of patients with acquired brain injury. Rehabilitation Nursing. 2011; 36(1):3-12. [PubMed: 21290959]

52. Institute for Patient- and Family-Centered Care. Patient- and family-centered care: Core concepts. 2015. http://www.ipfcc.org/pdf/CoreConcepts.pdf

53. Paterson B, Scott-Findlay S. Critical issues in interviewing people with traumatic brain injury. Qualitative Health Research. 2002; 12(3):399-409. [PubMed: 11918104]

54. Perry J. Interviewing people with intellectual disabilities. The International Handbook of Applied Research in Intellectual Disabilities. 2004:116-131.

55. Turkstra LS, Dixon TM, Baker KK. Theory of mind and social beliefs in adolescents with traumatic brain injury. NeuroRehabilitation. 2004; 19(3):245-256. [PubMed: 15502257]

56. Coco K, Tossavainen K, Jääskeläinen JE, Turunen H. Support for traumatic brain injury patients' family members in neurosurgical nursing: A systematic review. Journal of Neuroscience Nursing. 2011; 43(6):337-348. [PubMed: 22089411]

57. Wongvatunyu S, Porter EJ. Mothers' experience of helping young adults with traumatic brain injury. Journal of Nursing Scholarship. 2005; 37(1):48-56. [PubMed: 15813587]

58. Arango-Lasprilla JC, Quijano MC, Aponte M, Cuervo MT, Nicholls E, Rogers HL, Kreutzer J. Family needs in caregivers of individuals with traumatic brain injury from Colombia, South America. Brain Injury. 2010; 24(7-8):1017-1026. [PubMed: 20545455] 
59. Murray IR, Ahmed I, White NJ, Robinson CM. Traumatic anterior shoulder instability in the athlete. Scandinavian Journal of Medicine \& Science in Sports. 2013; 23(4):387-405. [PubMed: 22738342]

60. Verhaeghe S, Defloor T, Grypdonck M. Stress and coping among families of patients with traumatic brain injury: a review of the literature. Journal of Clinical Nursing. 2005; 14(8):10041012. [PubMed: 16102152]

61. Lefebvre H, Pelchat D, Levert M-J. Interdisciplinary family intervention program: a partnership among health professionals, traumatic brain injury patients, and caregiving relatives. Journal of Trauma Nursing. 2007; 14(2):100-113. DOI: 10.1097/01.JTN.0000278797.51407.d5 [PubMed: 17579331]

62. Leith KH, Phillips L, Sample PL. Exploring the service needs and experiences of persons with TBI and their families: The South Carolina experience. Brain Injury. 2004; 18(12):1191-1208. [PubMed: 15666564]

63. Chan J. Carers' perspective on respite for persons with acquired brain injury. International Journal of Rehabilitation Research. 2007; 30(2):137-146. [PubMed: 17473625]

64. Turner BJ, Fleming J, Ownsworth T, Cornwell P. Perceived service and support needs during transition from hospital to home following acquired brain injury. Disability and Rehabilitation. 2011; 33(10):818-829. [PubMed: 20812814] 


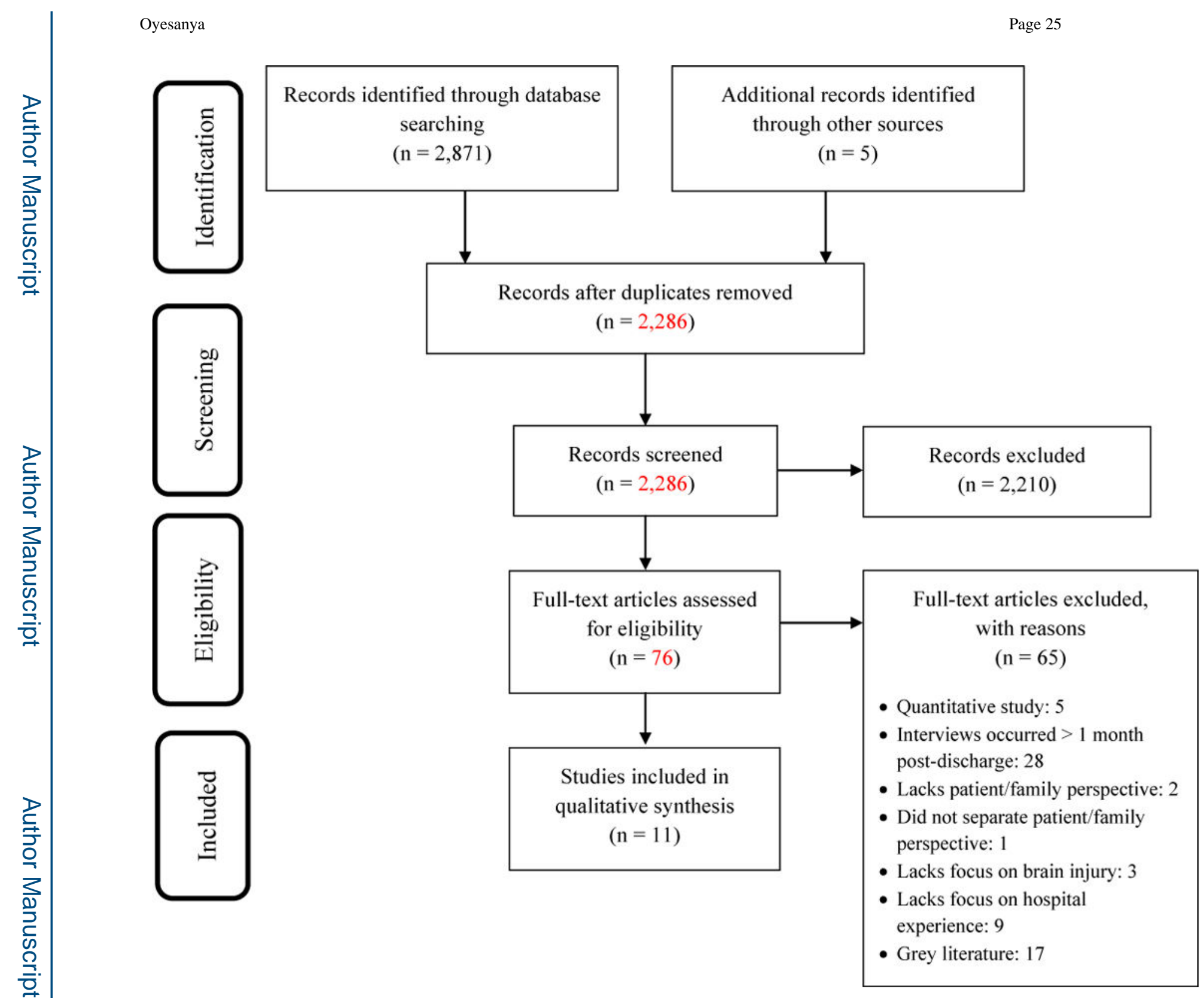

Figure 1.

PRISMA Flow Chart 
Table 1

\section{Eligibility Criteria}

\begin{tabular}{|c|c|}
\hline Criteria & Inclusion/Exclusion Criteria \\
\hline Patients & $\begin{array}{l}\text { Patient participants must: a) be age } 18 \text { years or older; b) be diagnosed with an acquired brain injury (e.g., moderate-to- } \\
\text { severe traumatic brain injury or some form of acquired brain injury [stroke, aneurysm, etc.]); c) be hospitalized or } \leq \text { one } \\
\text { month post-discharge at the time of the study; d) have had a qualitative interview conducted during the hospital stay or } \leq \\
\text { one month post-discharge; and e) be fluent in English language. Exclusion criteria for patients: a) age } 17 \text { years or } \\
\text { younger; b) sustained some sort of brain injury but did not receive hospital care; and c) diagnosis of brain injury but are } \\
\text { part of a drug trial or intervention study. }\end{array}$ \\
\hline Family Members & $\begin{array}{l}\text { Family member participants must: a) be age } 18 \text { years or older; b) have a family member who was diagnosed with an } \\
\text { acquired brain injury (e.g., moderate-to-severe traumatic brain injury or some form of acquired brain injury [stroke, } \\
\text { aneurysm, etc.]); c) be an immediate or extended family member of patient; d) have a family member who was } \\
\text { hospitalized or } \leq \text { one month post-discharge at the time of the study; e) have had a qualitative interview conducted during } \\
\text { the patient's hospital stay or } \leq \text { one month post-discharge; and f) fluent in English language. Exclusion criteria for family } \\
\text { members: a) age } 17 \text { years or younger; b) non-family member (e.g., friends, bystanders, strangers). }\end{array}$ \\
\hline Patients' Diagnoses & $\begin{array}{l}\text { This systematic review included studies with samples of patients diagnosed with: a) specific or unspecified moderate-to- } \\
\text { severe ABI; b) moderate-to-severe TBI; and c) stroke. Exclusion criteria for patients' diagnoses. The following } \\
\text { exclusion criteria were applied for diagnoses: a) mild TBI; b) severe TBI with diagnosis of persistent vegetative state; } \\
\text { and c) non-brain injury related condition/disease. }\end{array}$ \\
\hline Study Focus & $\begin{array}{l}\text { Studies focusing on these topics relevant to the patient's and family's hospital stay experience were included: a) views } \\
\text { or experience of; b) attitudes; c) perspectives or perceptions; d) needs or wants; e) thoughts or feelings. Exclusion } \\
\text { criteria for study focus. Studies focusing on the following topics were excluded: a) views/experience that did not relate } \\
\text { to the hospital stay; b) healthcare providers' perspective; c) patient/family views/experience of the therapy patients } \\
\text { receive while hospitalized. }\end{array}$ \\
\hline Types of Studies & $\begin{array}{l}\text { All qualitative research studies published as a journal article, including qualitative findings from mixed-methods studies } \\
\text { were included. All quantitative research studies and grey literature (e.g., dissertation studies, books, clinical guidelines, } \\
\text { published abstracts, newsletters, conference proceedings, etc.) were excluded. }\end{array}$ \\
\hline$\overline{\text { Setting }}$ & $\begin{array}{l}\text { Studies focusing on following hospital settings were included in this review: a) intensive or critical care; b) acute care; c) } \\
\text { general care; d) [acute] inpatient rehabilitation; and e) tertiary care settings. Exclusion criteria for settings including the } \\
\text { following settings: a) outpatient; b) community; and c) home. }\end{array}$ \\
\hline
\end{tabular}




\section{Table 2}

\section{Search Terms ${ }^{1}$}

\begin{tabular}{|l|l|}
\hline Focus & Key words and phrases \\
\hline Population (Patients) & Clients OR Patients OR client* OR patient* \\
\hline Population (Family Members) & $\begin{array}{l}\text { Family OR "Family Members" OR Caregivers OR famil* OR husband* OR wife OR wiv* OR child* OR } \\
\text { parent* OR relative* OR grandparent* OR grandmother* OR grandfather* OR aunt* OR uncle* OR cousin* } \\
\text { OR sibling* OR sister* OR brother* OR niece* OR nephew* }\end{array}$ \\
\hline Patients" Diagnoses & $\begin{array}{l}\text { "Traumatic Brain Injury" OR brain injur* OR TBI OR traumatic brain injur* OR head injur* OR "traumatic } \\
\text { brain injury" OR ABI OR “acquired brain injury" OR "brain injury" OR "head injury" }\end{array}$ \\
\hline Study focus and type of studies & $\begin{array}{l}\text { "Qualitative Research" OR Attitudes OR Emotions OR view* OR experience* OR perspective* OR } \\
\text { attitude* OR perception* OR need* OR want* OR feeling* OR qualitative* OR story OR stories }\end{array}$ \\
\hline Setting & $\begin{array}{l}\text { Hospitalization OR Hospitals OR Rehabilitation OR Intensive Care OR Treatment OR hospital* OR } \\
\text { inpatient* OR inpatient OR ICU OR rehabilitation OR "intensive care" OR "acute care" OR therap* OR } \\
\text { therapy }\end{array}$ \\
\hline
\end{tabular}

1 Table 2 details an example of search terms from the PsycInfo literature search. Subject headings were used where applicable and available. An '*', denotes a truncated term. Some phrases have quotation marks around them as a signal to the database to provide studies that used that exact phrase. 


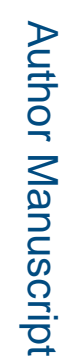

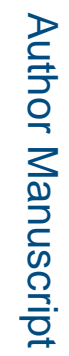

를

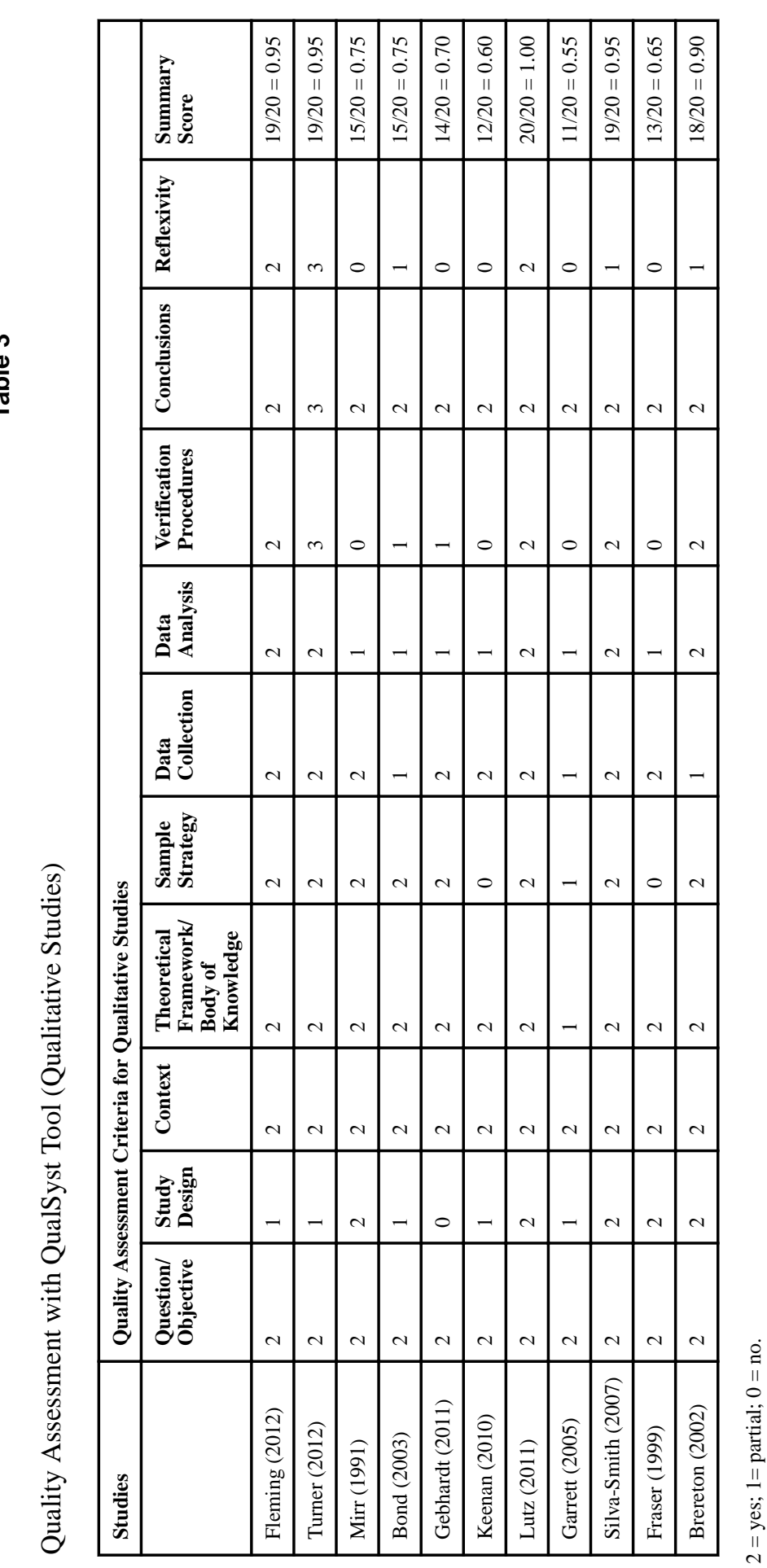

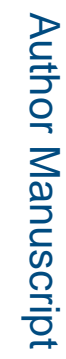

Brain Inj. Author manuscript; available in PMC 2018 January 05. 


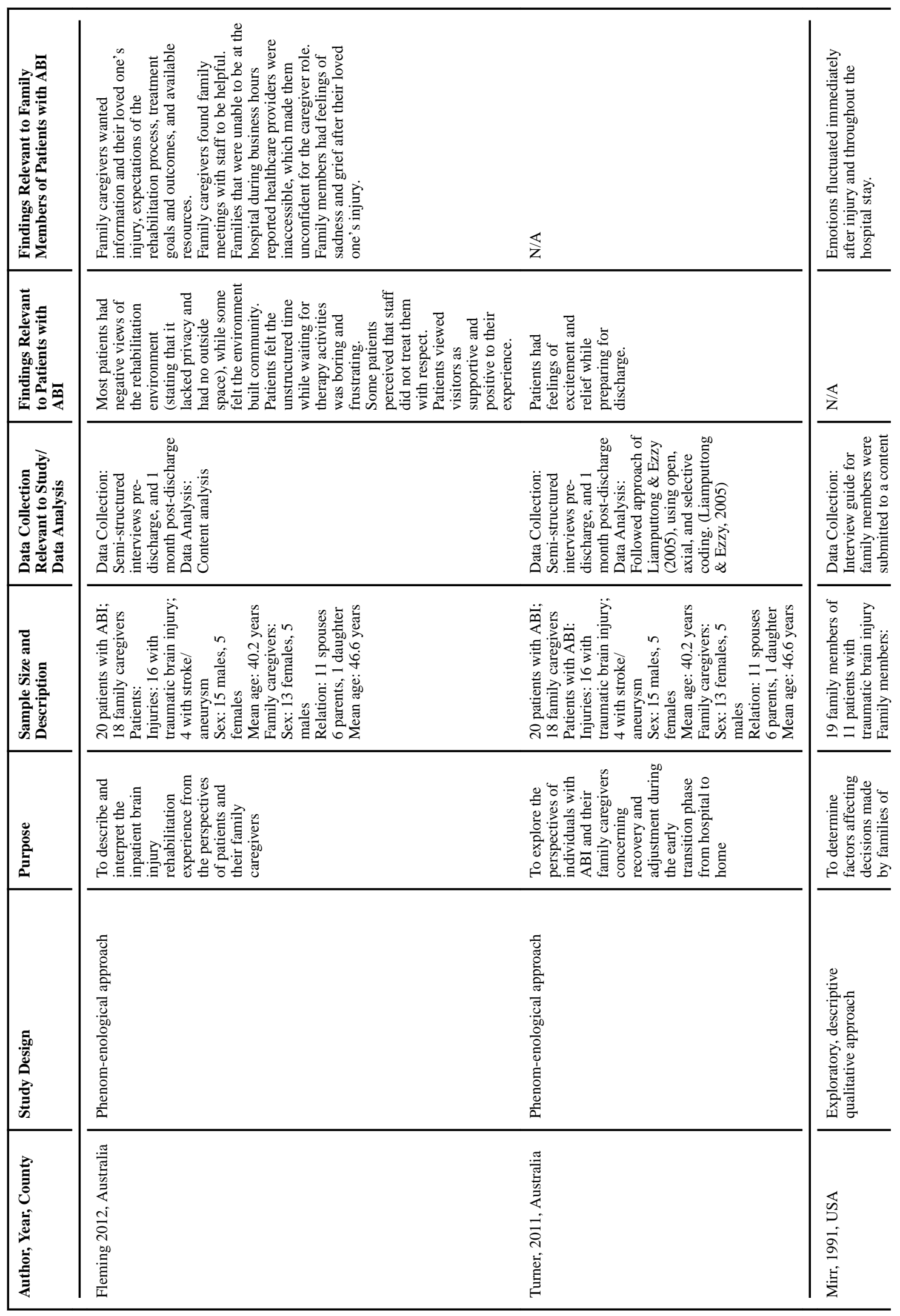

Brain Inj. Author manuscript; available in PMC 2018 January 05. 


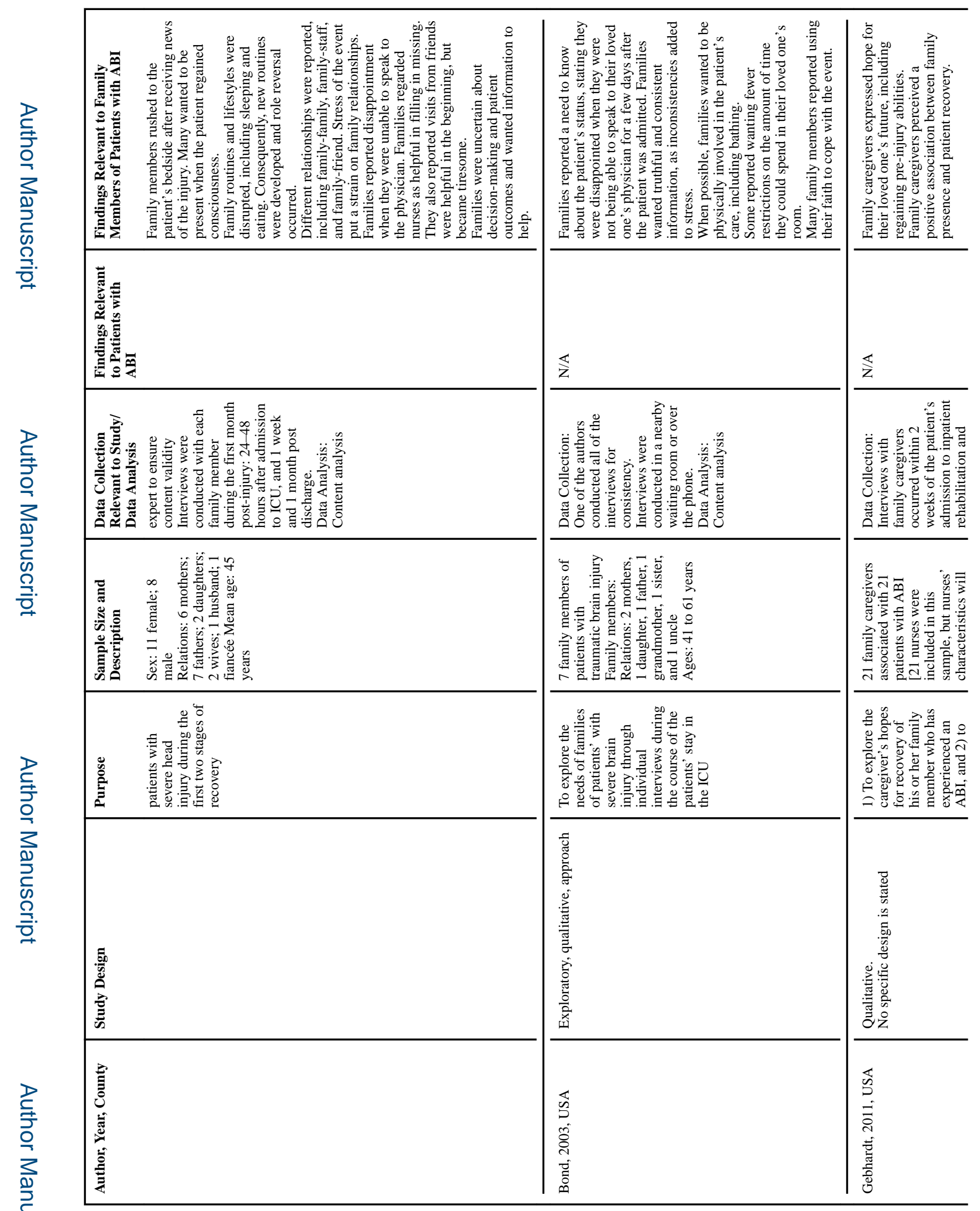

Brain Inj. Author manuscript; available in PMC 2018 January 05. 


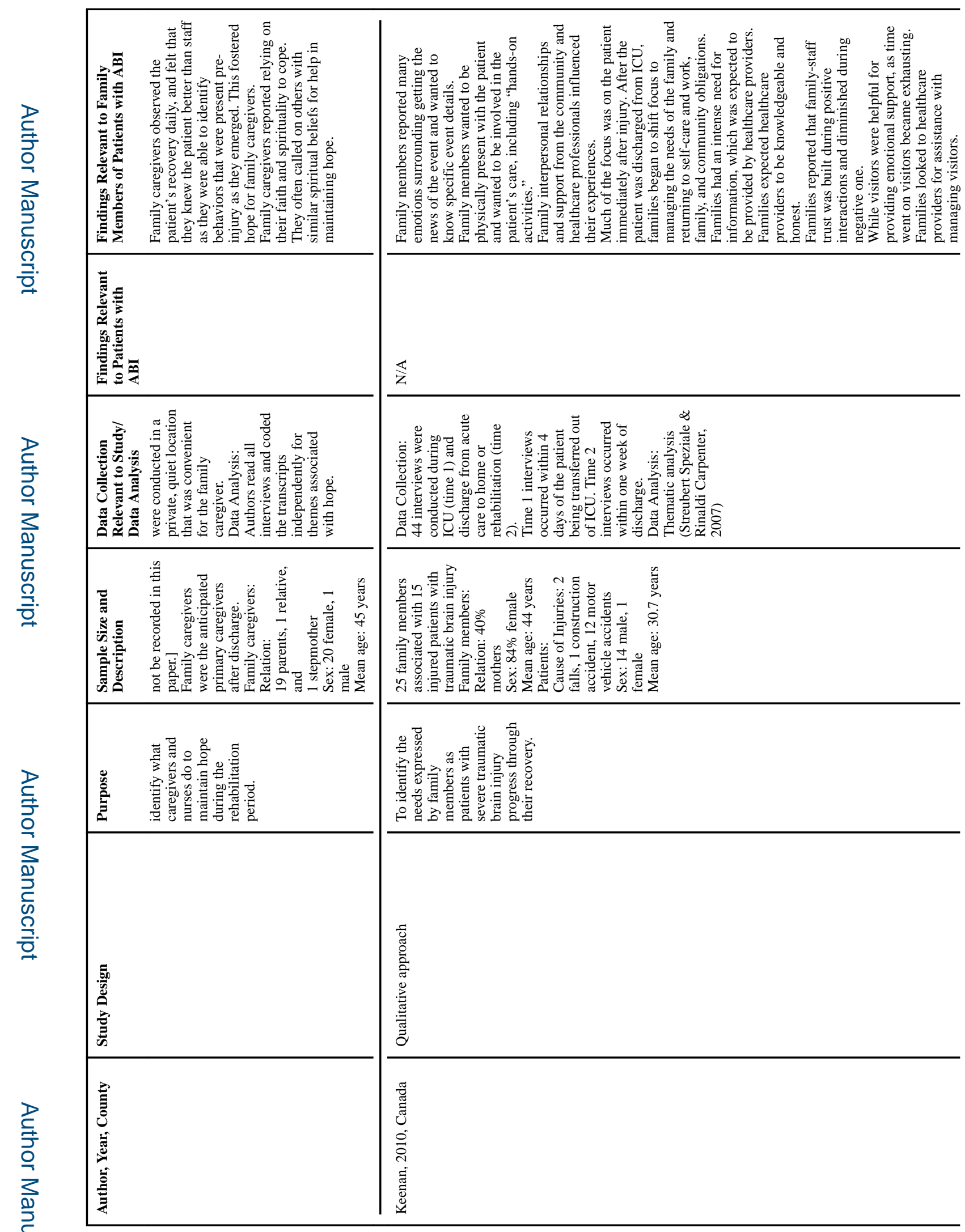

Brain Inj. Author manuscript; available in PMC 2018 January 05. 


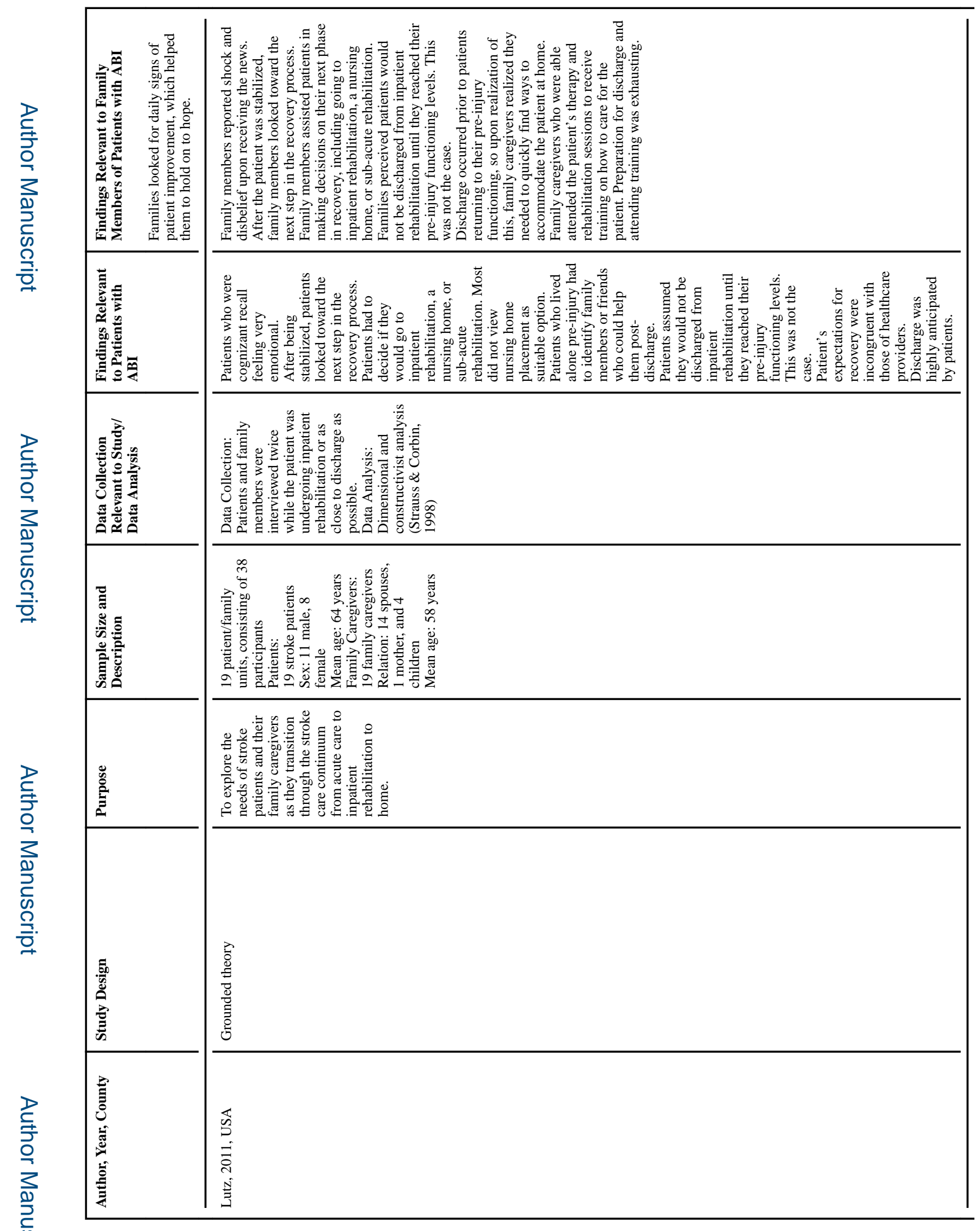

Brain Inj. Author manuscript; available in PMC 2018 January 05. 


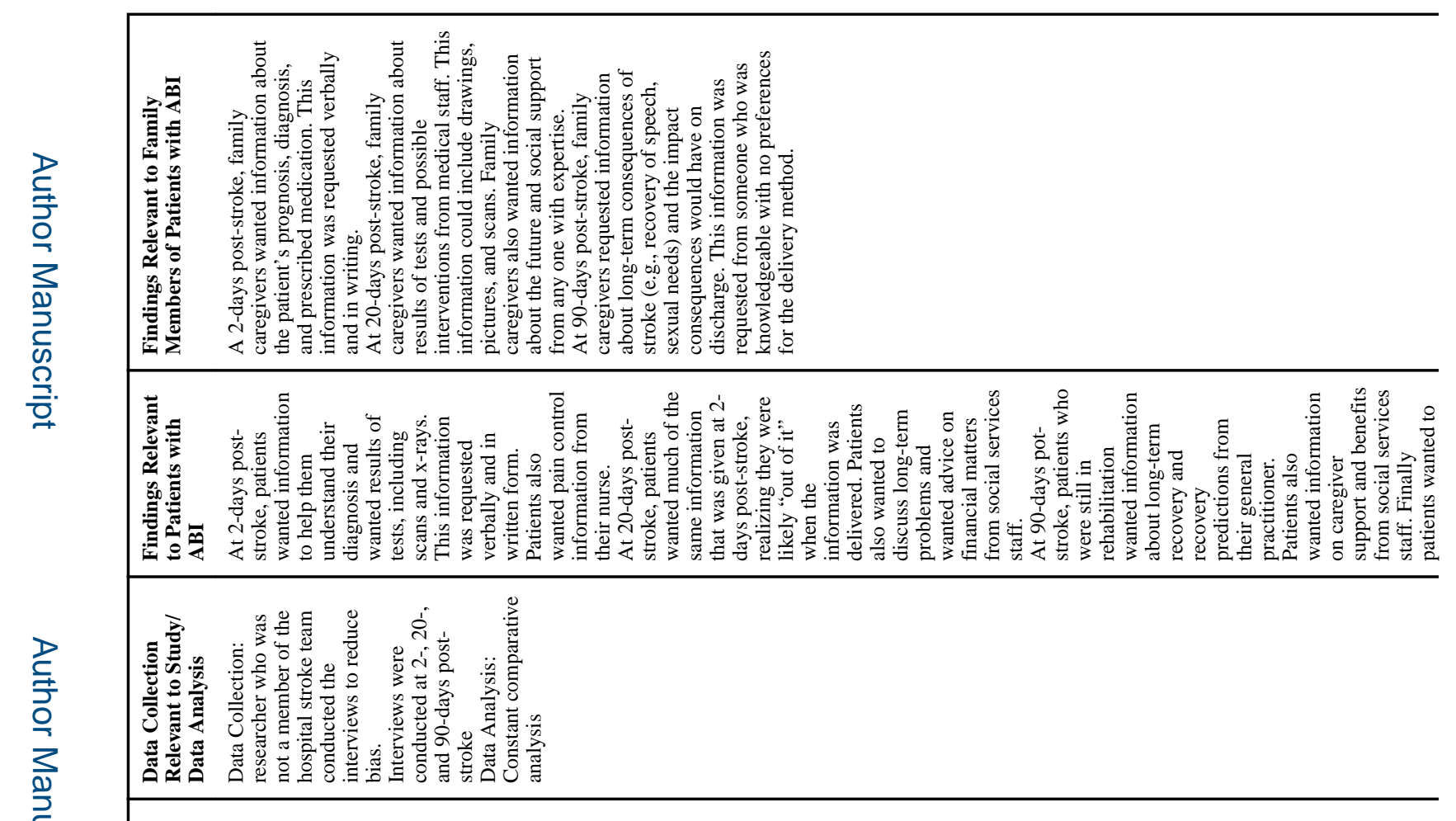

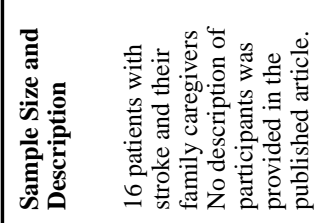

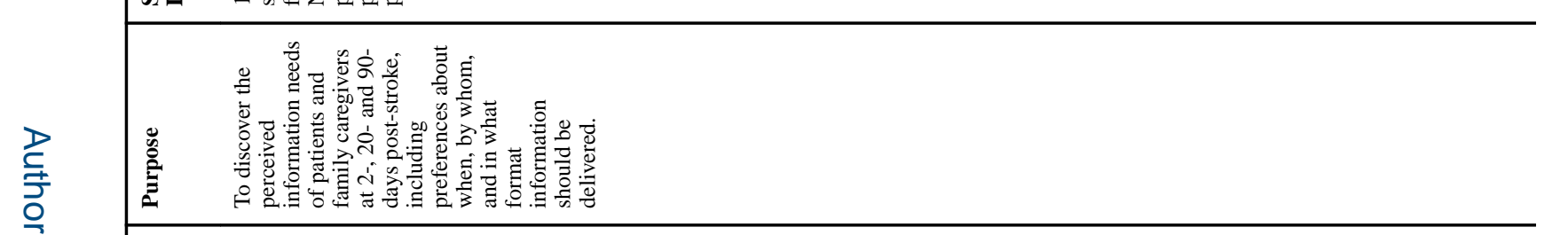

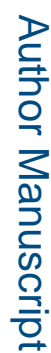

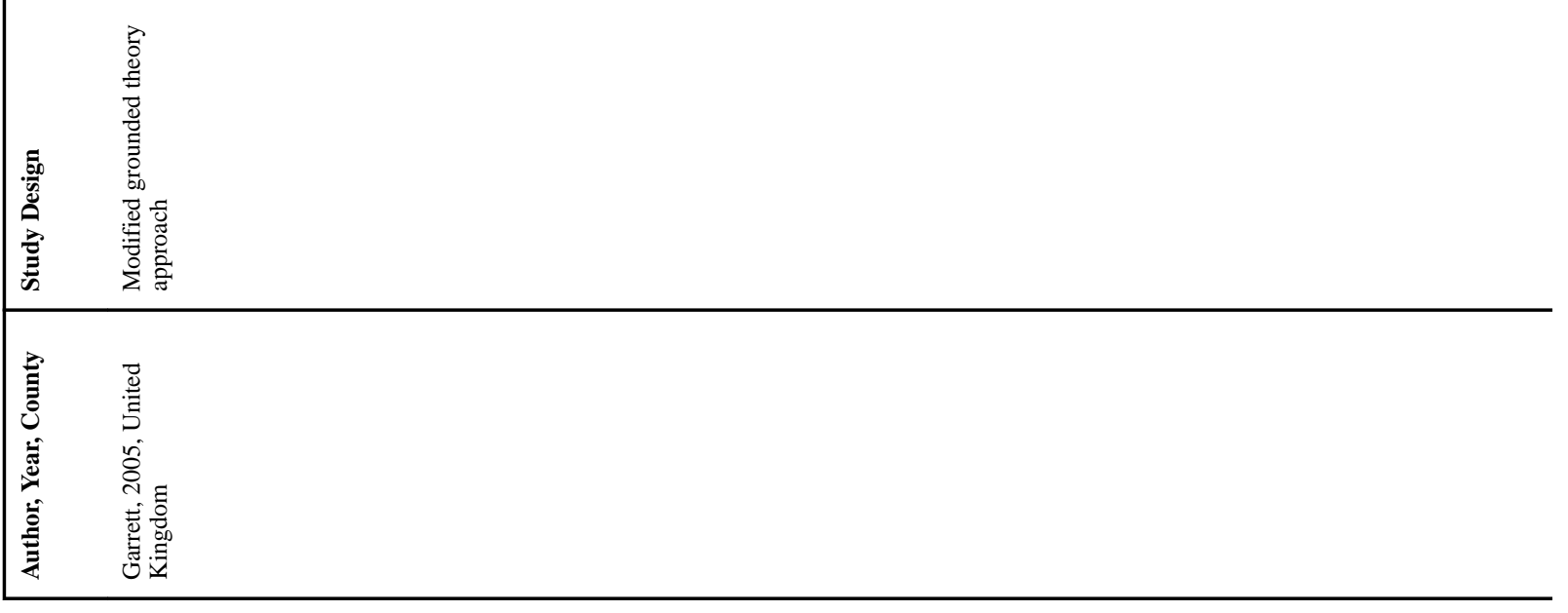

Brain Inj. Author manuscript; available in PMC 2018 January 05. 


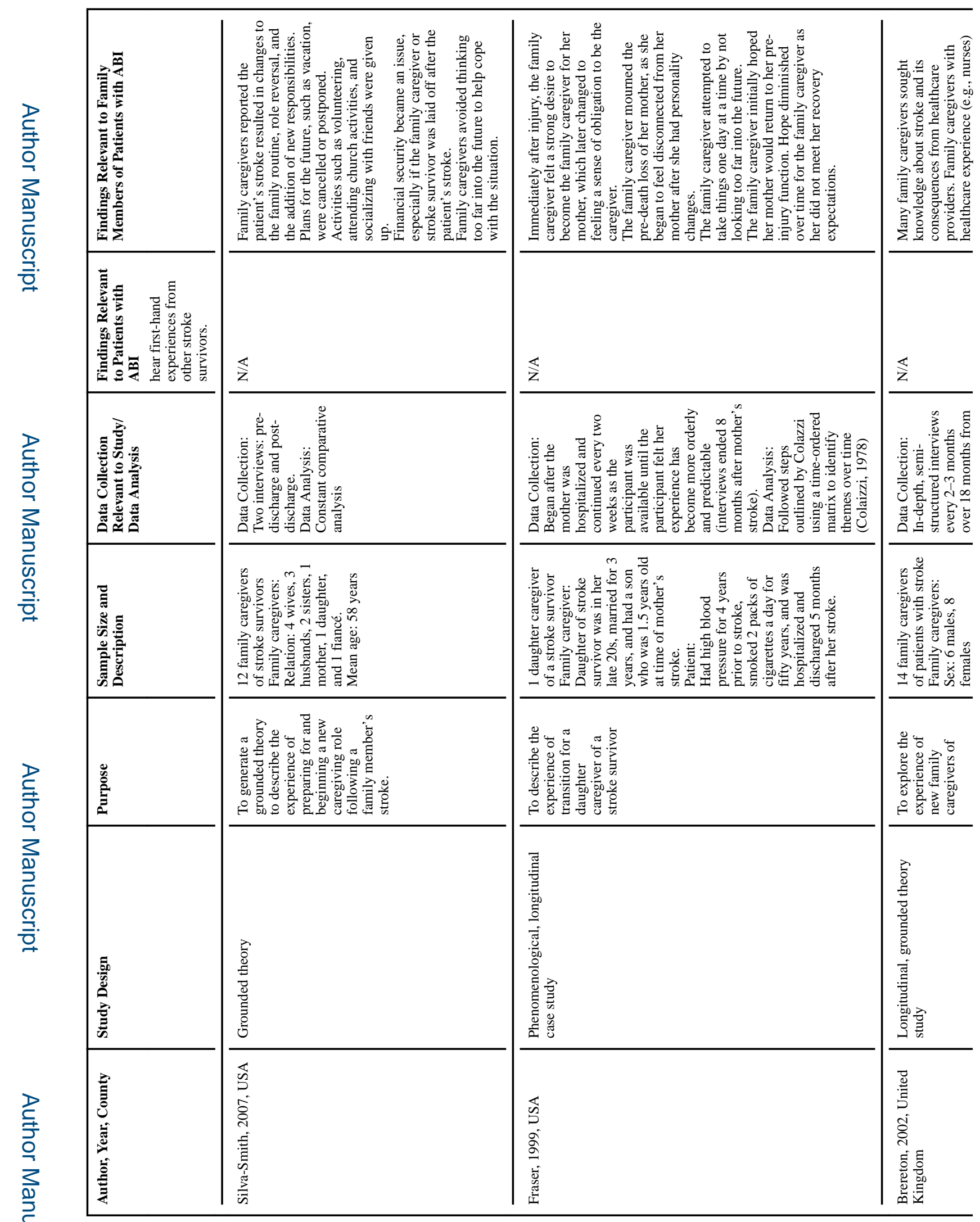

Brain Inj. Author manuscript; available in PMC 2018 January 05. 


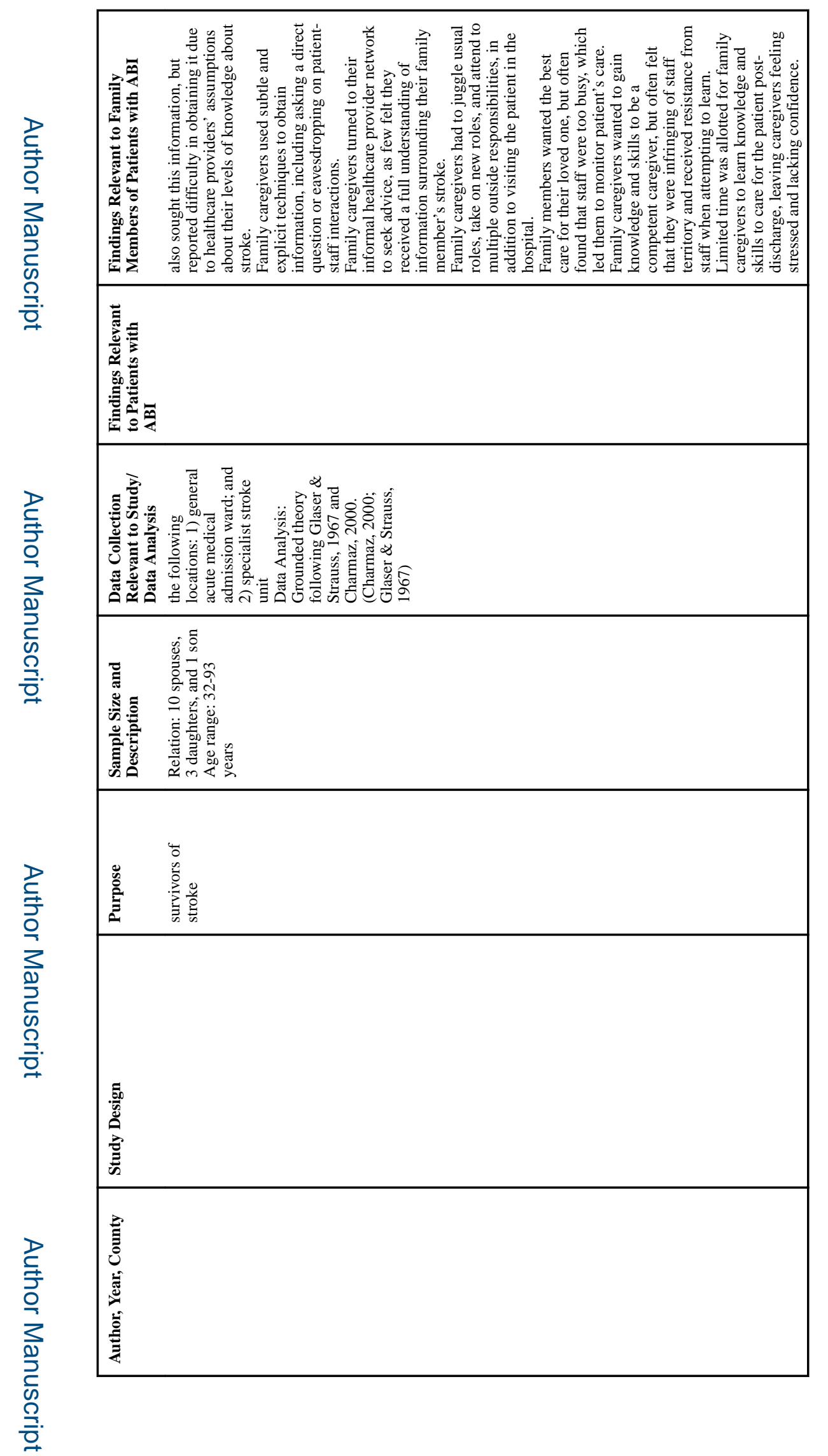

Brain Inj. Author manuscript; available in PMC 2018 January 05. 


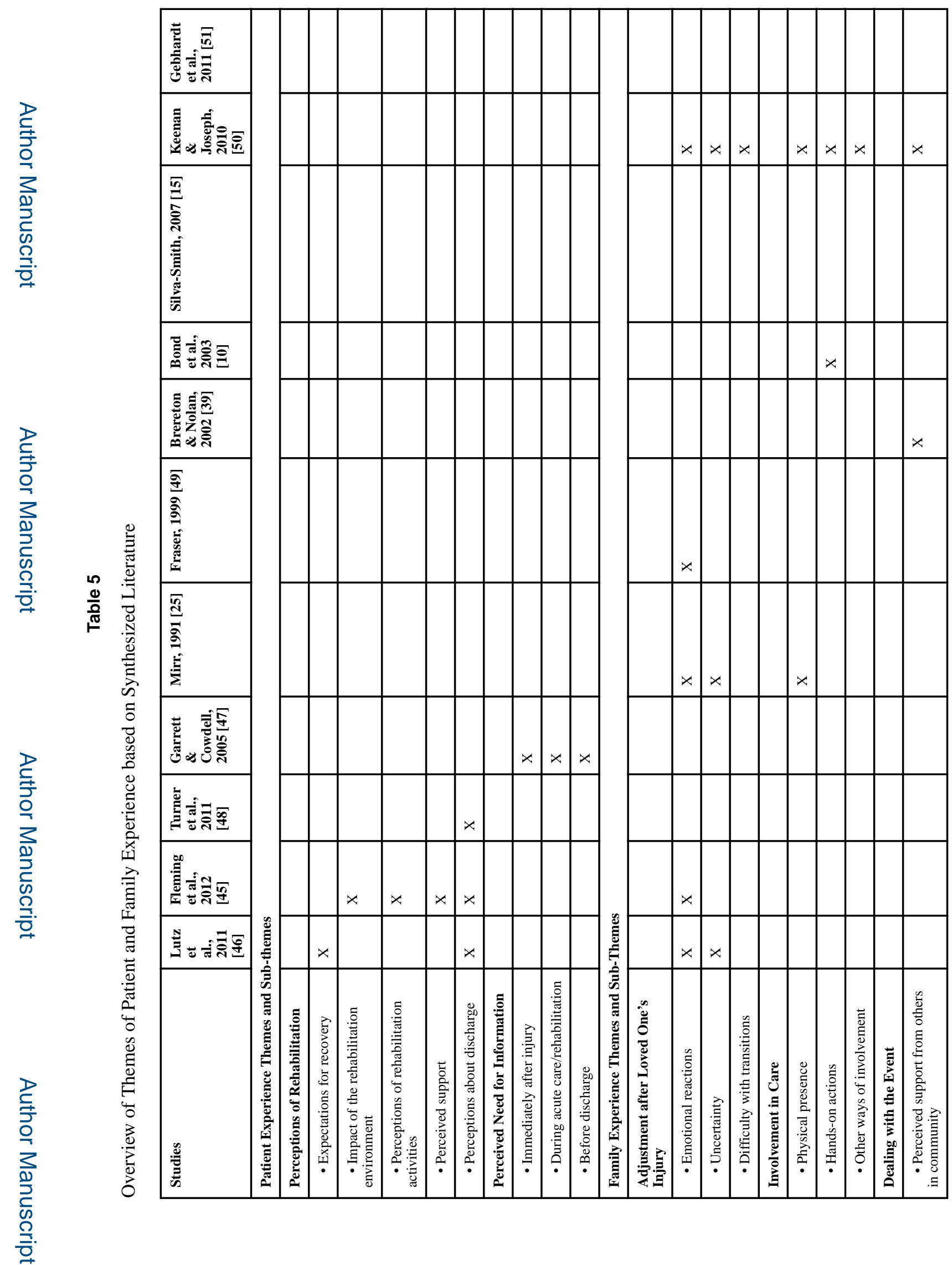

Brain Inj. Author manuscript; available in PMC 2018 January 05. 

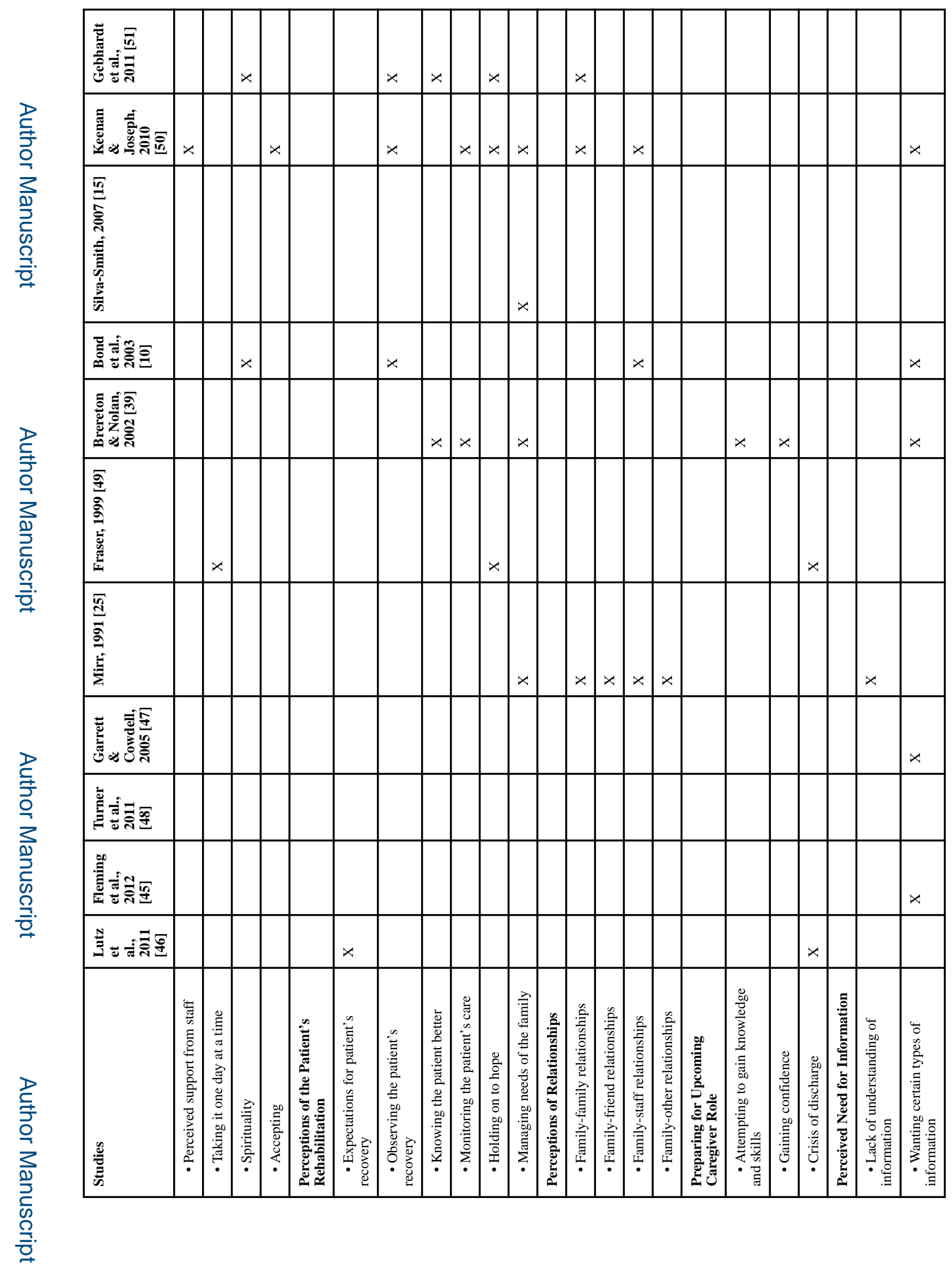

Brain Inj. Author manuscript; available in PMC 2018 January 05. 


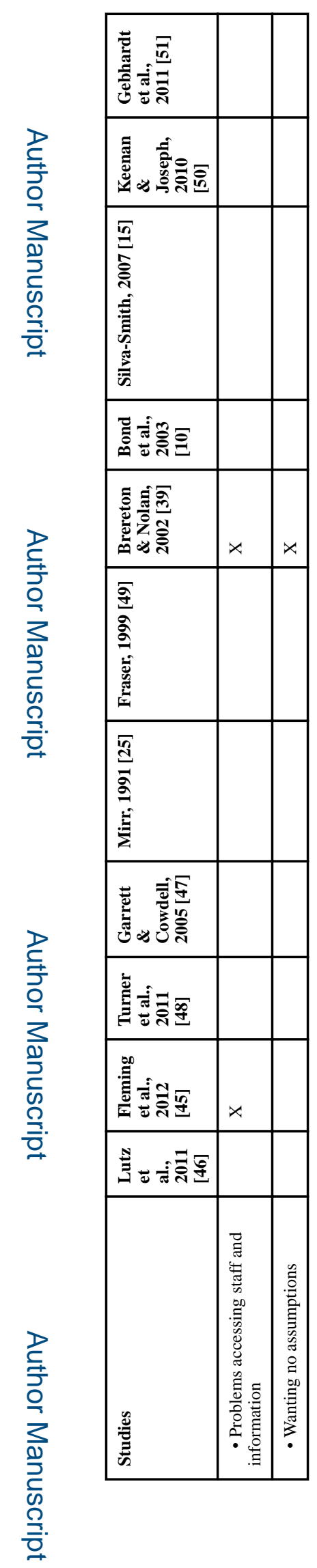

Brain Inj. Author manuscript; available in PMC 2018 January 05. 